
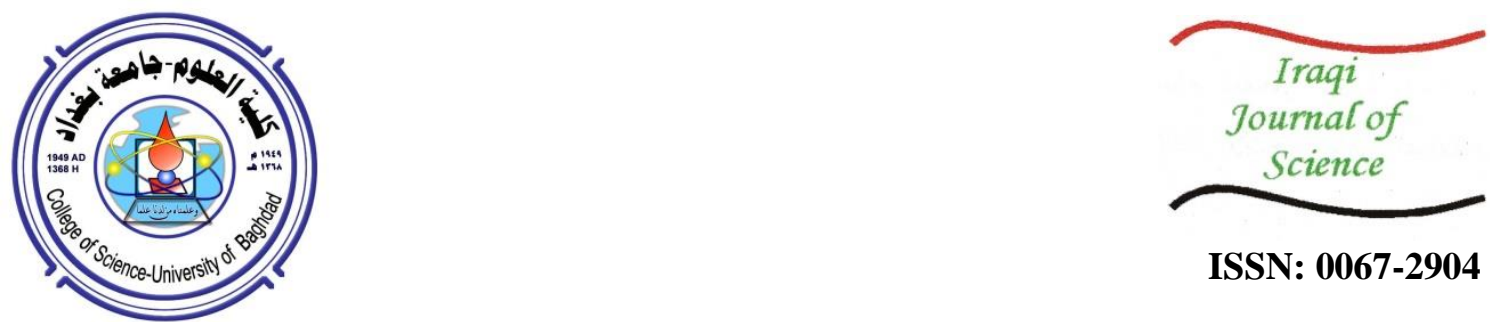

ISSN: 0067-2904

\title{
Paleostress Analysis of the Northeastern Limb of Pulkhana Anticline /NE Iraq: Implications for Arabian Plate Tectonic Evolution
}

\author{
Burkan S. Othman', Zakariya Q. Jadda*2 \\ ${ }^{1}$ Department of Applied Geology, College of Science, Kirkuk University, Kirkuk Iraq \\ ${ }^{2}$ Schlumberger Oil Company, Basra, Iraq
}

Received: 8/6/2019

Accepted: $21 / 1 / 2020$

\begin{abstract}
Pulkhana anticline is located in Tuzhurmatu area, about $50 \mathrm{~km} \mathrm{SE}$ of Kirkuk city. The study area forms a part of the Zagros Folded Zone which is situated in the unstable shelf of Iraq within the physiographic zone called Foothill Zone (in the middle of Hemrin- Makhul subzone). The north eastern limb of the anticline reaches to $50^{\circ}$ and the dip of the south western limb reaches to $70^{\circ}$. The core of the structure comprises the rocks of Fat'ha Formation surrounded by rocks of Injana and Mukdadiya Formations, whereas Bai-Hasan Formation forms the slopes of the low hills surrounding the anticline. These Formations range in age from Middle Miocene to Pliocene. More than 761 readings of joint planes were collected from 20 stations within 5 traverses in the study area. The study of joint sets and system was within Injana and Mukhdadiya formations, along traverses with 3-5 stations for each travers track. The results showed the presence of two sets of tension joints (bc, ac) and five sets of shear joints, through defining the maximum stress axis $(\sigma 1)$ and acute angle dividers for these conjugate joints. It was determined that two directions of Paleostress are present in the area, which are NE-SW and NW-SE. The direction of the first major stress (NE-SW) is orthogonal with, or normal to, the fold axis in the study area, which can be considered as a horizontal component which resulted from oblique collision of Arabian and Eurasian Plates. This old compressive stress is the reason behind the formation of the tension joint (ac) and shear joints, where the sets (ac) and system are perpendicular-semi perpendicular to the bedding plane, as they were formed at an early stage of folding. Also, the ) joint was formed in five tectonic stages with different time intervals. Joints formed in different tectonic stages, in the study area, are attributed to oblique collision of Arabian and Eurasian plates and counter clockwise rotation of Arabian plate relative to Eruasian plate.
\end{abstract}

Keywords: paleostress, pulkhana anticline, tension joints, shear joints, Arabian plate, compressive strength.

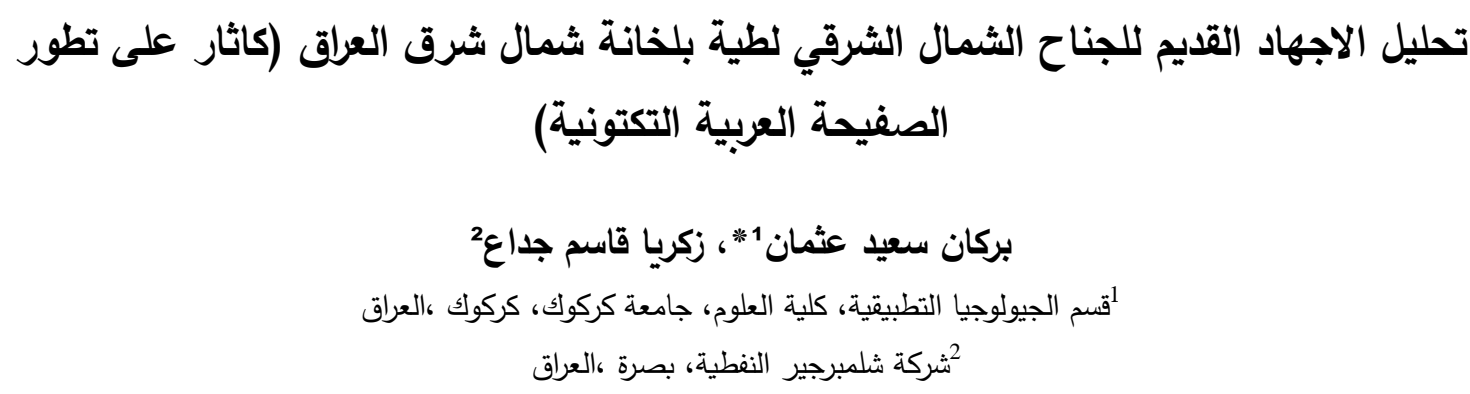

*Email: selimburkan2015@gmail.com 


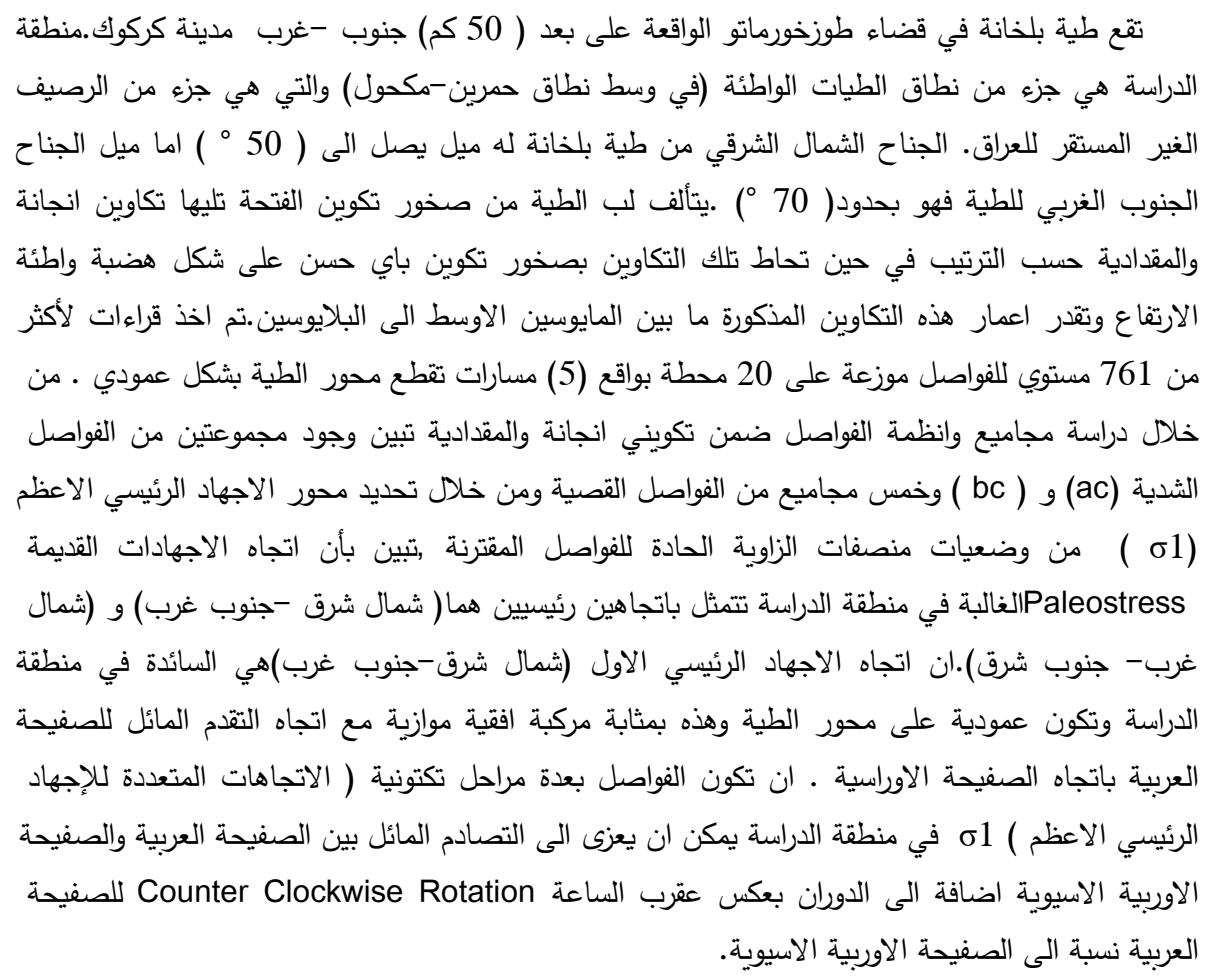

\section{1- Introduction}

The state of stress in the rocks is generally anisotropic and is defined by stress ellipsoid axes, which characterize the magnitude of the principal stresses [1]. Stress analysis is a useful and popular tool for structural and seismological elements [2]. If an ellipsoidal body undergoes positive compression, the longest axis is the ellipsoid's major stress $(\boldsymbol{\sigma} \mathbf{1})$, the intermediate axis is the intermediate stress $(\boldsymbol{\sigma} \mathbf{2})$, and the shortest axis is the minimum stress ( $\mathbf{\sigma 3})$ [3]. Several paleostress inversion methods have been developed using graphical and analytical means. The orientation and shape of the stress ellipsoid, with respect to earth's surface, controls the type, orientation and slip sense of faults developed in an area [4]. Extensional structures grow perpendicular to a minimum principal stress $(\boldsymbol{\sigma 3})$ [5]. ( $\mathbf{\sigma 1})$ is oriented perpendicular to compressional structures, and for strike- slip fault and other tectonic structures produced by shearing, the intermediate stress is vertical [6,7]. Although paleostress analysis proved to be empirically valid and successful, there are some limitation to its usage [8]. Paleostress inversion studies are used to understand the effects of past slip events along active fault by making use of deflection in the orientations of the stress axes to recognize stress perturbations near the major fault $[9,10]$. Standard paleostress inversion techniques are used only for determining the orientations and relative magnitude (stress ratio) of the regional principal stress axes [4]. It is assumed that slip on the activated pre-existing planes of weaknesses and newly developed faults occur in accordance with the orientation and relative magnitudes of the principal stresses [11].

When the fault cannot be observed by paleostress analysis, joints have been used instead [12]. Joints as paleostress markers provide the record of stress orientation at the time of propagation and are often extensional in nature $[13,14]$. Joints can be used separately or collectively with other structures, including contractional fractures such as stylolites, to constrain the stress field that led to their formation [12]. The assumption is that the fractures formed in the same homogenous stress field, i.e. related to the same deformational event that the rocks themselves are fairly homogenous, do not significantly perturb the stress field in their vicinity, and also that the structures have not rotated significantly since their initiation [15].

This study aims to rebuild the evolution of the collision between the northeastern parts of the Arabian plate with the Eurasian plate, in addition to determining the plaeostress in the northeast limb of the Pulkhana anticline. In order to achieve that, we analyzed more than 760 joint slip surfaces in the study area. 


\section{2- Geological Setting}

The study area is located between latitudes ( $\left.34^{\circ} 39^{\prime} 34.9^{\prime \prime} \mathrm{N}_{-} 35^{\circ} 01^{\prime} 15.6^{\prime \prime}\right)$ and longitudes ( $44^{\circ} 31^{\prime}$ 52.7" E_ 45 00' 57.3" E). The northwestern end of the study area is located in Salah Al- Deen Governorate, while the southeastern end is located in Diyala Governorate (Figure-1). The study area forms a part of the Zagros Folded Zone which is situated within the physiographic zone called Foothill Zone (in the middle of Hemrin- Makhul subzone) in the unstable shelf of Iraq [16] (Figure-2). Pulkhana anticline (study area) is one of the important structural elements in Hemrin- Makhul subzone. It has asymmetric long anticline trends (NW_SE). The anticline is overthrust from the NE in the exposed rocks and the most of the SW limb of the anticline is absent beneath the recent deposits (Figure-3). The dip of the north eastern limb of the anticline reaches $50^{\circ}$, while the dip of the south western limb reaches to $70^{\circ}$. Accordingly, Pulkhana anticline is an upright anticline depending on its axial plane, while it is a gentle anticline depending on its interlimb angle (Table-1\& Figure-4), according to the classification of a previous study [17].

This information must be moved to the first page

The core of the structure comprises rocks of Fat'ha Formation surrounded by rocks of Injana and Mukdadiya formations, whereas Upper Bakhtiary Formation forms the slopes of the low hills surrounding the anticline. These Formations range in age from Middle Miocene to Pliocene [18].

The present study was conducted in the exposed Fat'ha, Injana, and Mukdadiya Formations. In the study area, the exposed Fat'ha Formation includes $641.8 \mathrm{~m}$ thick layers of gypsum, limestone, claystone and marl. Gypsum is white, occasionally light grey and medium grey, moderately hard to hard, massive, occasionally showing nodules, bands and rosy shapes, randomly fractured, and occasionally filled by clay minerals. Limestone beds are pale yellowish brown to dark yellowish brown, moderately hard to hard, thinly to thickly bedded, fossiliferous, fractured, occasionally recrystallized, and showing karst features in some places, while anhydritic and silty in other places. Claystone is reddish brown, occasionally moderately yellowish brown, soft, and eroded. Injana Formation is comprised of $1393.6 \mathrm{~m}$ thick layers of sandstone and claystone. Sandstone is light brownish grey to light olive grey, occasionally reddish brown, firm to hard, fine to coarse grained, thickly bedded, poorly cemented, calcareous, occasionally ripple marked, and cross bedded. Claystone is moderately reddish brown to moderately brown, soft to firm, thinly bedded, moderately bedded in some places, silty, and fractured. Mukdadiya Formation includes $655.3 \mathrm{~m}$ thicklayers of pebbly sandstone, sandstone and claystone. Sandstone is light olive grey to light grey, occasionally yellowish grey, soft to firm, coarse to very coarse grained, poorly cemented, cemented in some places, moderately bedded, occasionally cross bedded, silty, fractured, and pebbly. The size of the pebbles ranges $1-1.5 \mathrm{~cm}$. Claystone is moderately brown to light brown, soft to firm, thinly to moderately bedded, silty, fractured, and eroded. Marl is greenish grey to very pale green, soft, thinly bedded, and eroded. Bai-Hassan Formation is the youngest Formation in the study area, as recognized on the basis of the first appearance of thick conglomeratic bed, according to previously reported criteria $[19,20]$. It is characterized by $741 \mathrm{~m}$ thick layers, calcareous and poorly cemented conglomerates with intercalated light olive grey sandstone lenses and light brown to moderately yellowish brown claystone. Conglomerate consists of gravels of different sizes $(1-15 \mathrm{~cm})$. The shape of the gravels is spherical, rod, or bladed . 


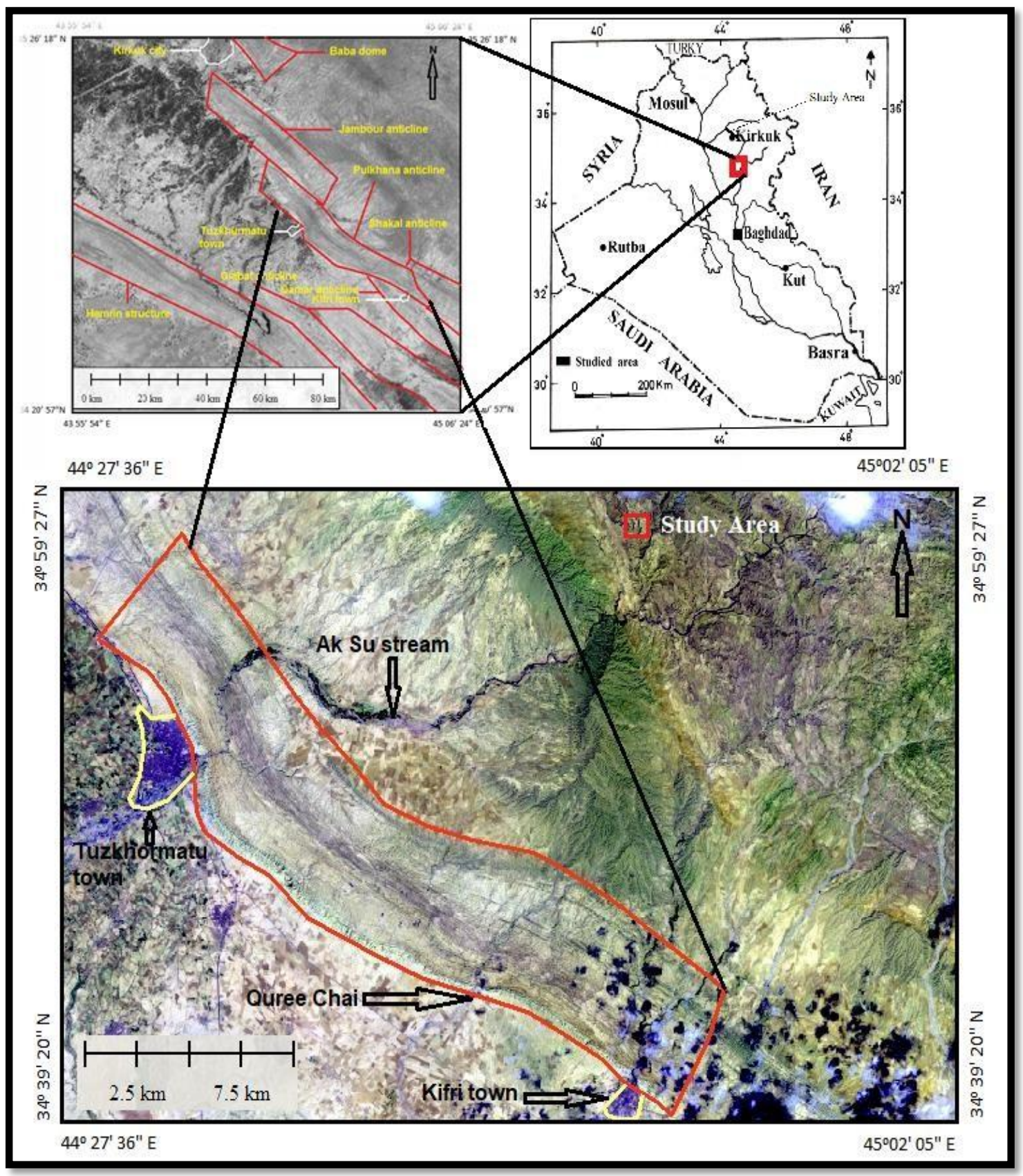

Figure 1-Location map of the study area. 


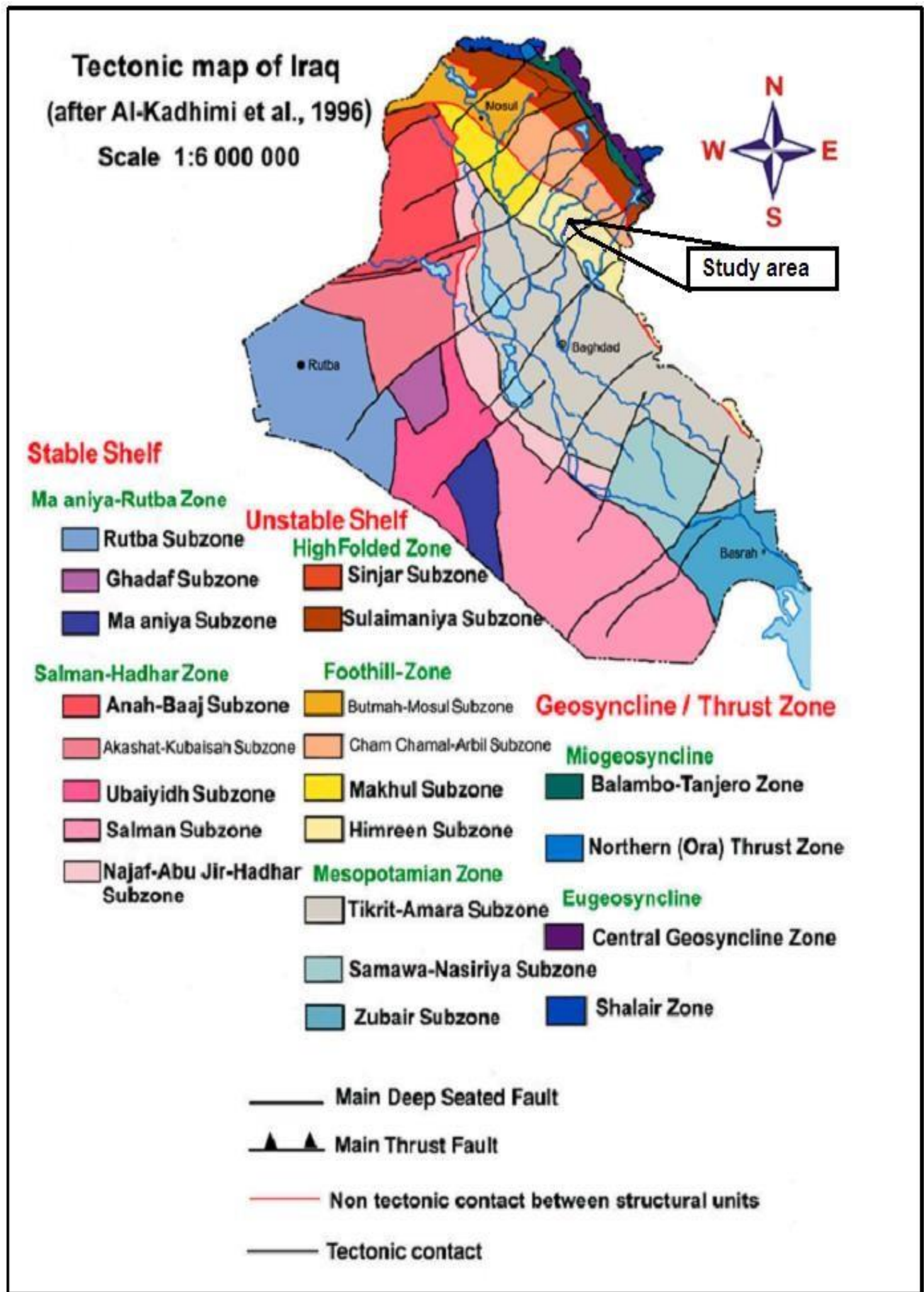

Figure 2-Tectonic map of Iraq [19]. 


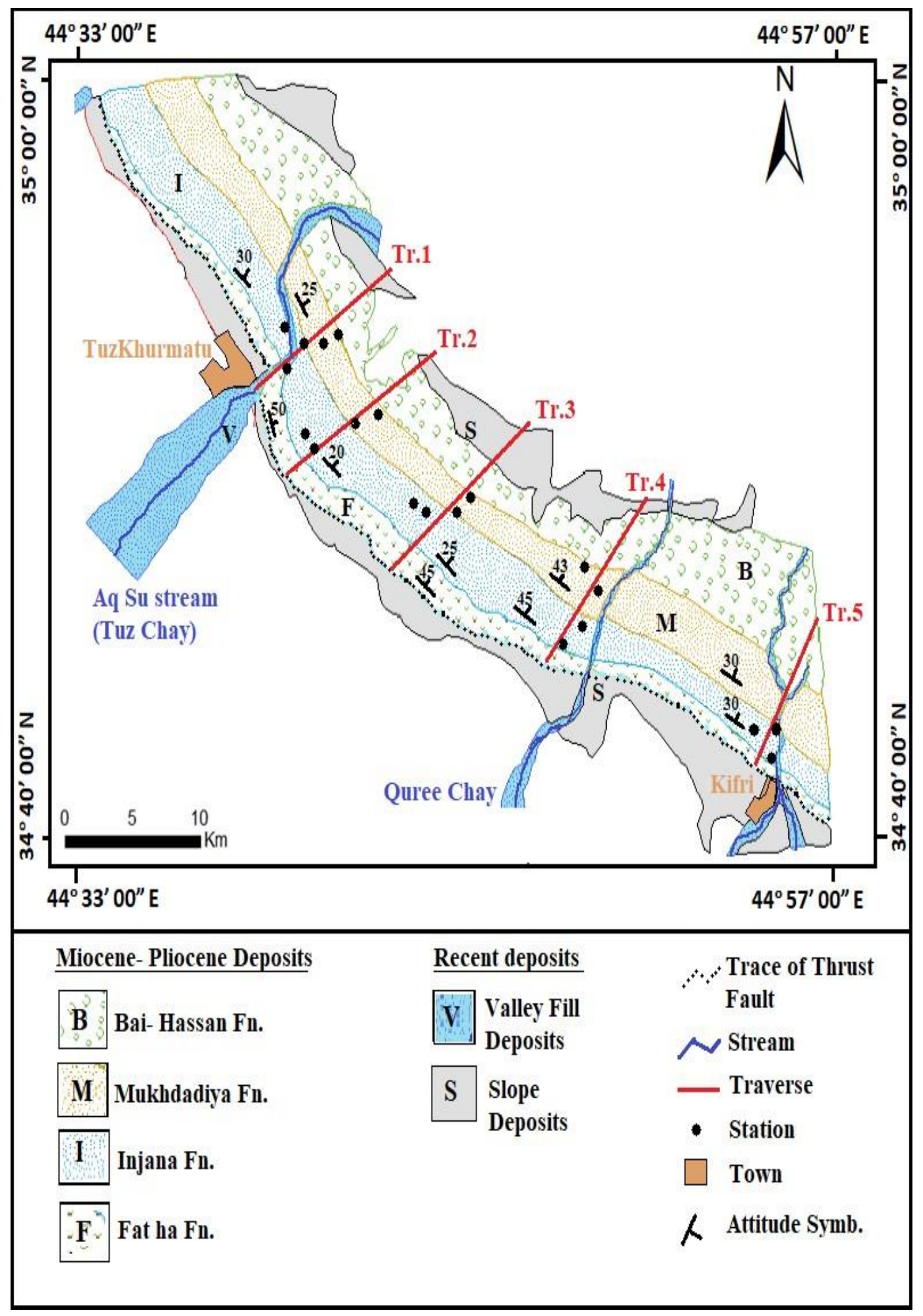

Figure 3-Geological map of the study area. 
Table 1-The classification of Pulkhana anticline depending on its axial plane and interlimb angle.

\begin{tabular}{|c|c|c|c|c|c|c|}
\hline \multirow{2}{*}{ Type } & Interlimb Angle & Type & \multicolumn{2}{|c|}{ Dip of Axial Plane } & \multicolumn{2}{c|}{ Attitude of Limbs } \\
\hline \multirow{3}{*}{ Gentle } & \multirow{2}{*}{120} & \multirow{2}{*}{$\begin{array}{c}\text { Dip } \\
\text { Angle }\end{array}$} & Strike & $\begin{array}{c}\text { Dip } \\
\text { Angle }\end{array}$ & Strike \\
\cline { 4 - 7 } & & & 80 & 318 & $50 / 70$ & $318 / 138$ \\
\hline
\end{tabular}

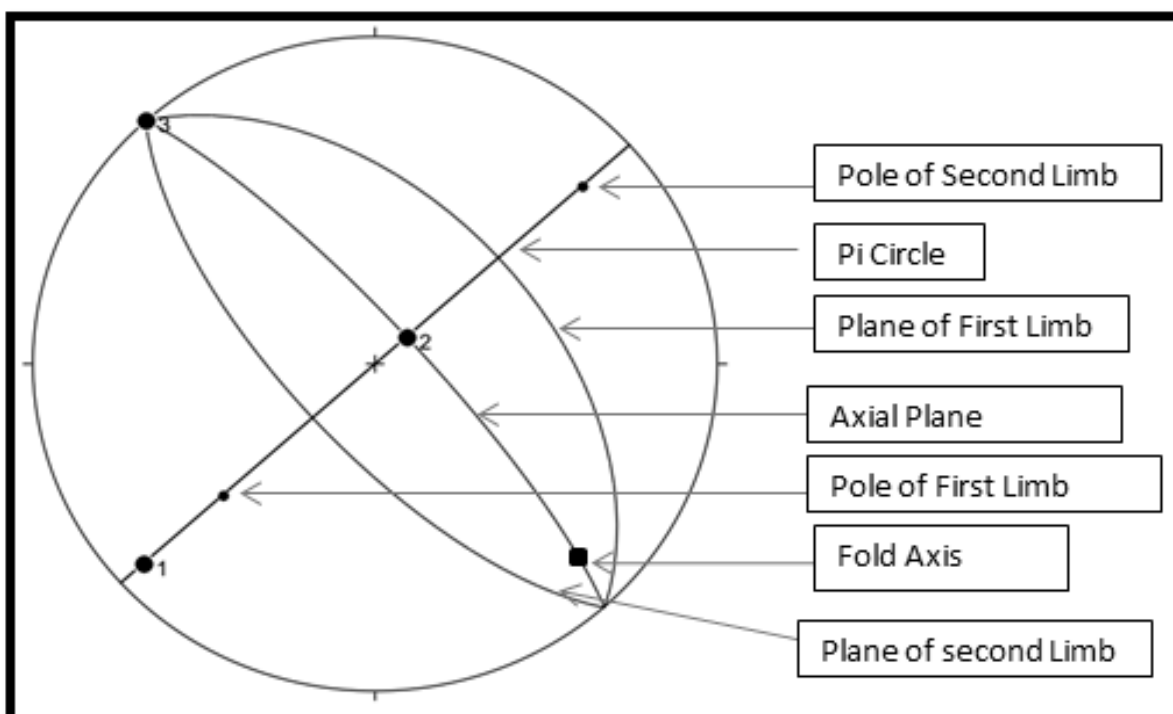

Figure 4-Pi- diagram of pulkhana anticline.

\section{3- Methodology}

The methodology of this investigation included three stages; first, the stage of collection of data from academic books, researches, papers, maps and satellite images as well as personal communications. Second, field work stage which started with 3 field exploration trips and 13 field work trips to the study area. The required equipment included a compass device (Brunton) to measure bedding planes and joint planes and GPS devices (Garmin type) to calculate the location attitude in 5 traverses (Figure- 3). Field observations and calculations included:

- Measuring the dip direction/ dip angle for about 761 joint planes within an area of $5 \times 10 \mathrm{~m}$ for each station.

- $\quad$ Brief description of the exposed rocks of each formation in the study area.

Desk work stage included:

- Analyzing and describing joints data by stereographic projection.

- Calculating the paleostress direction of the conjugate joints by measuring their acute bisector , using Win- Tensor software.

- $\quad$ Preparing the topographic map of the study area by using GIS software.

\section{4- Results}

\section{Paleostress analysis}

In this study, conjugate shear joints were used for analyzing paleostress.

\section{4-1 joints}

Joints are among the most common of all geological features. Hardly any outcrop of rock exist that does not have some types of joints through it. They provide the sequence of tectonic events during which the joints were formed and the physical characteristics of the rocks in which they occur [21]. Studying of joints in rocks, however, shows that the joints' geometry is self-similar, which means that the joints have the same geometric pattern and spatial distribution regardless of whether the scale at which they are viewed is a microscopic scale, an outcrop scale, or a regional scale [21]. Because the outcrop scale is easy to observe and is the basis of most field geology studies, we emphasized the descriptive characteristics of joints at this scale. Joints in the study area were classified according to their geometrical relations with the three perpendicular geometrical axes (a, b \& c.), where (a) is 
parallel to the dip direction, (b) is parallel to the strike direction and (c) is perpendicular to $\mathbf{a}$ and $\mathbf{b}$. This classification was used by an earlier work [21], and followed by later reports [22-26] (Figure-5).

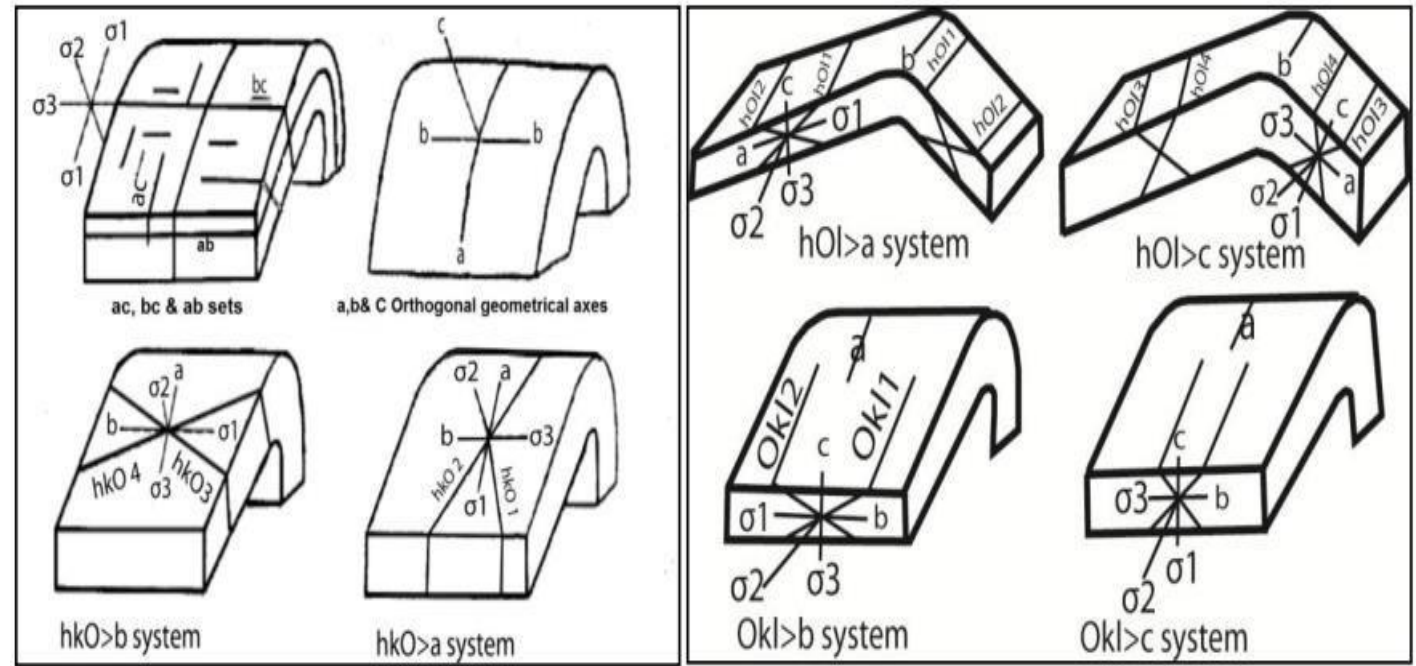

Figure 5-Geometrical classification of the joints with respect to three orthogonal geometrical axes [23].

\section{2-1-1 joints analysis in the study are}

Dip direction and dip angle were measured for the joint planes as well as the attitude of the bedding plane which contains the joints. The shear systems appeared either as individual or conjugate. Many collected data were neglected due to the nonexistence of the two conjugate joints of the system in the same station.

\section{Traverse 1/ station 1}

As shown in Figure-5, the (0kl) acute angle about the (c) shear system was recognized in this station.

Extensional stress was analyzed from the $(0 \mathrm{kl})$ acute about (c) axis with sub horizontal $(\sigma 3)$ attitude $\left(04^{\circ} / 325^{\circ}\right)$ associated with the final uplifting of the major fold (Figure- 7B). Figure- 7A shows field photos of the (0kl) acute about (c) in the study area. Individual (hk0) acute about (a), (hk0) acute about (b), (h0l) acute about (c) joint systems, and (ac) and (bc) joint sets were recognized in this station as well (Figure-6).

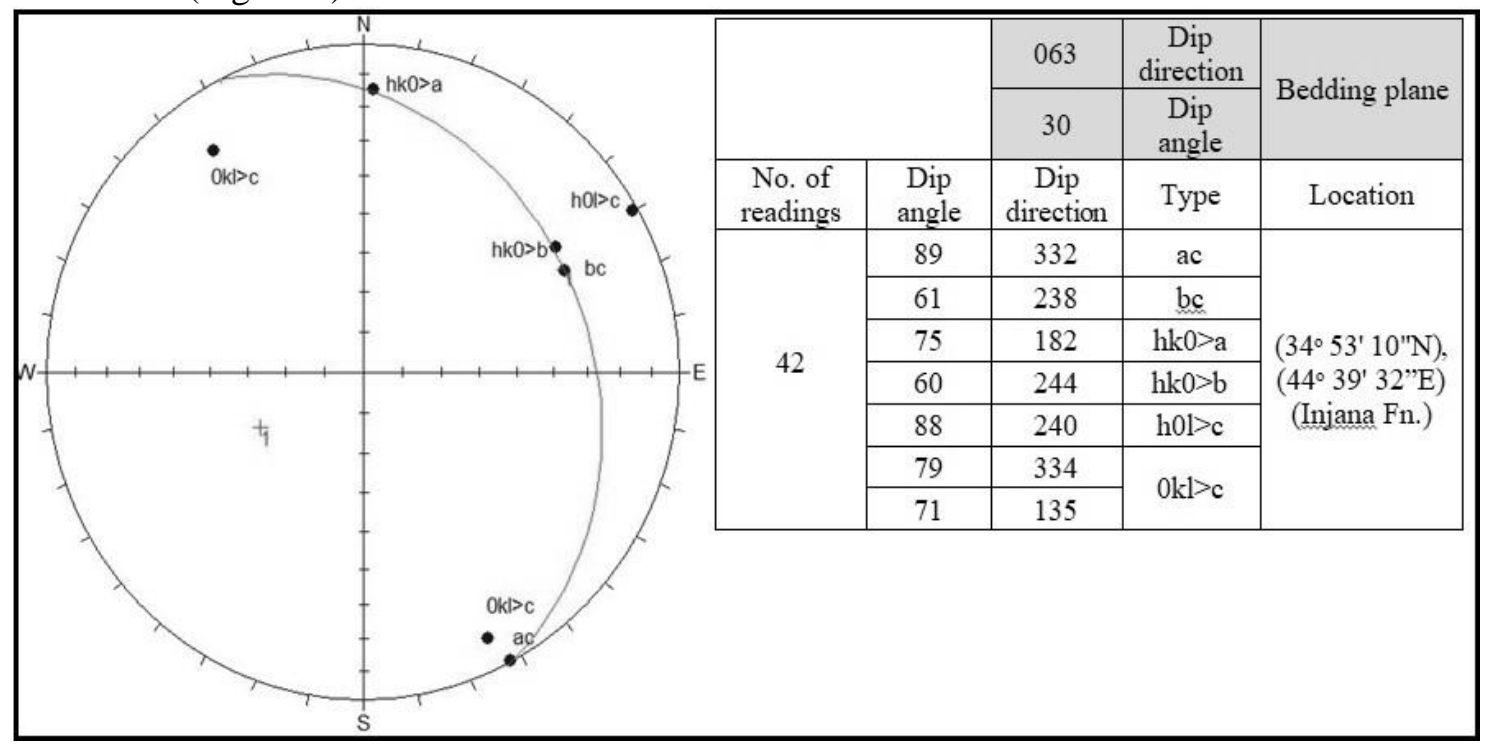

Figure 6-Stratigraphic projection of joint poles in traverse 1/ station 1. 


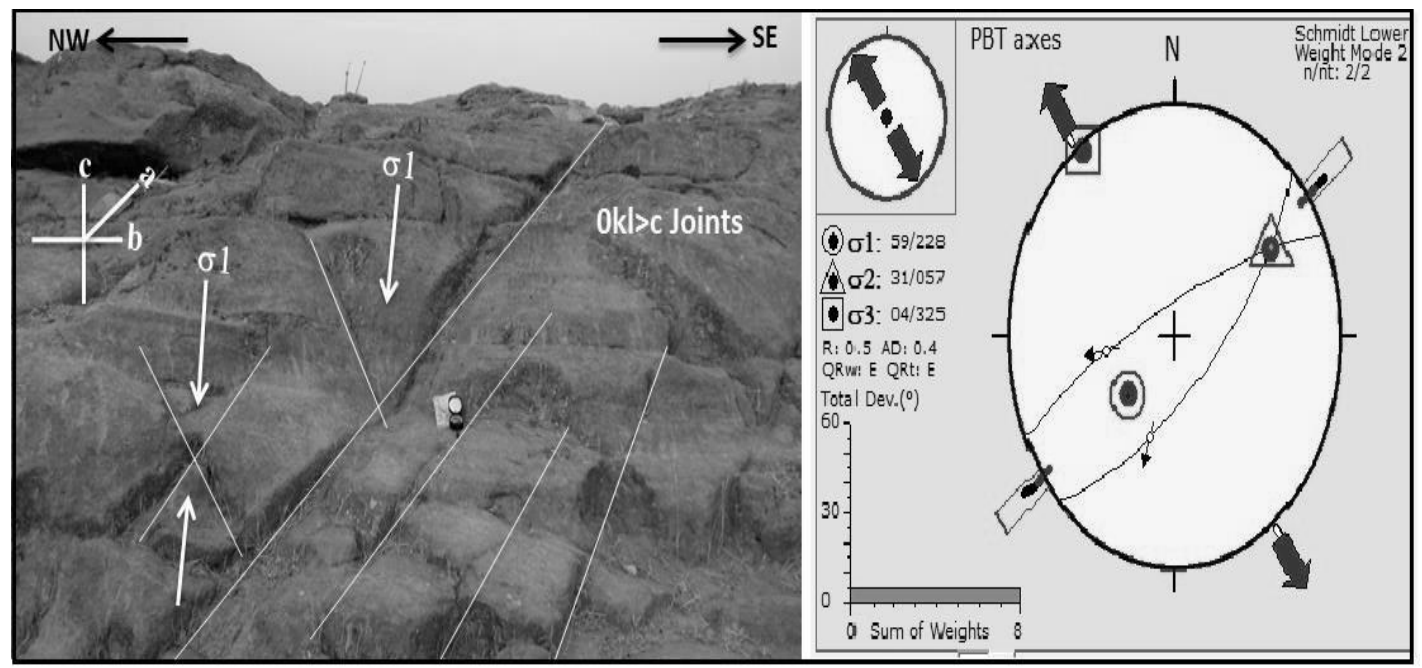

Figure 7A-field photo of (0kl) acute about (c); B: paleostress analysis from (0kl) acute about (c) in traverse $1 /$ station 1 .

\section{Traverse 1/ station 2}

NW-SE compressive stress from (hk0) acute about (b) axis shear system with $(\sigma 1)$ attitude $\left(05^{\circ} / 143^{\circ}\right)$ was recognized in this station (Figures- 8 and 9 ). Individual (hk0) acute about (a) system as well as (ac) and (bc) sets were also recognized in this station (Figure-8).

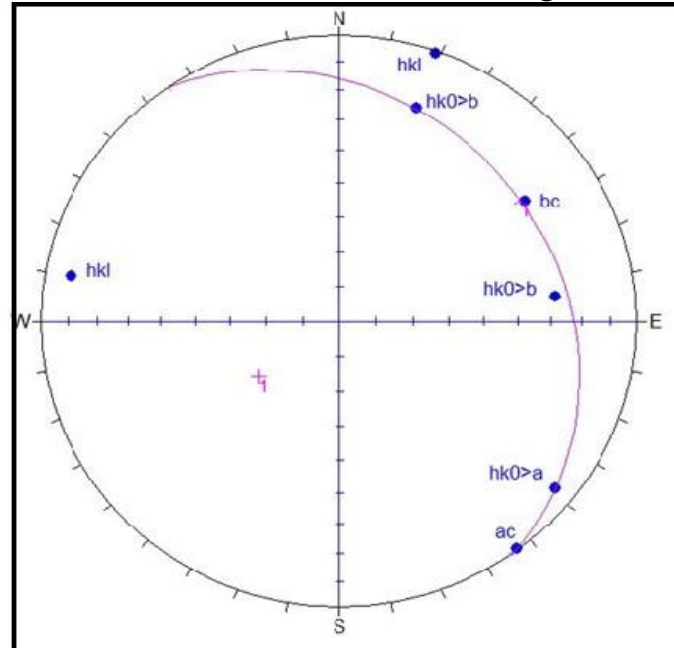

\begin{tabular}{|c|c|c|c|c|}
\hline & & 055 & $\begin{array}{c}\text { Dip } \\
\text { direction }\end{array}$ & \multirow{2}{*}{ Bedding plane } \\
\hline & & 27 & $\begin{array}{l}\text { Dip } \\
\text { angle }\end{array}$ & \\
\hline $\begin{array}{l}\text { No. of } \\
\text { readings }\end{array}$ & $\begin{array}{c}\text { Dip } \\
\text { angle }\end{array}$ & $\begin{array}{c}\text { Dip } \\
\text { direction }\end{array}$ & Type & location \\
\hline \multirow{7}{*}{42} & 89 & 323 & ac & \multirow{7}{*}{$\begin{array}{c}\left(34^{\circ} 53^{\prime} 31^{\prime \prime N}\right), \\
\left(44^{\circ} 39^{\prime} 57^{\prime \prime} \mathrm{E}\right) \\
\text { (Injana Fn.) }\end{array}$} \\
\hline & 64 & 236 & $\mathrm{bc}$ & \\
\hline & 82 & 309 & hk $0>a$ & \\
\hline & 62 & 263 & \multirow{2}{*}{$\mathrm{hk} 0>\mathrm{b}$} & \\
\hline & 68 & 199 & & \\
\hline & 89 & 199 & \multirow{2}{*}{ hkl } & \\
\hline & 80 & 100 & & \\
\hline
\end{tabular}

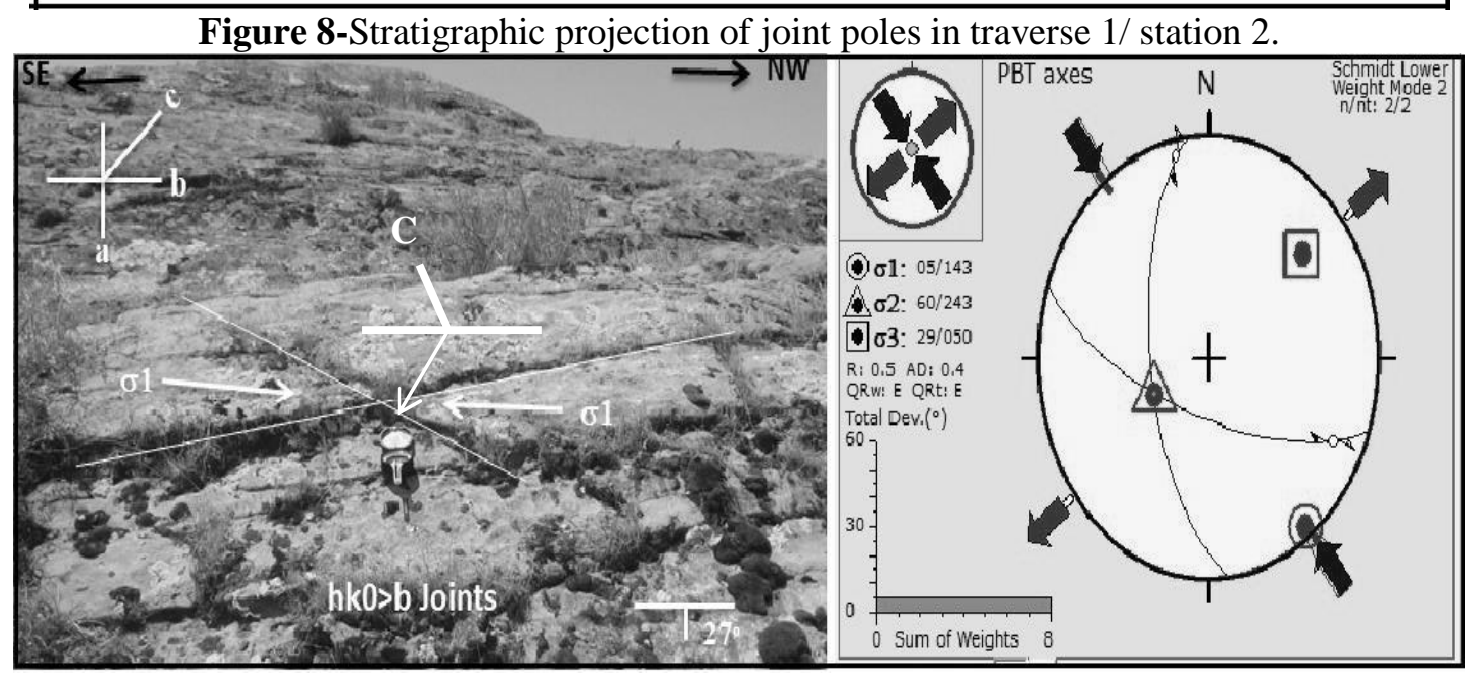

Figure 9 A-field photo of (hk0) acute about (b); B: paleostress analysis from (hk0) acute about (b) in traverse $1 /$ station 2 . 


\section{Traverse 1/ station 3}

NE-SW compressive stress from (hk0) acute about (a) axis shear systems with $(\sigma 1)$ attitude $\left(31^{\circ} / 072^{\circ}\right)$ and NW-SE compressive stress from (hk0) acute about (b) axis shear systems with $(\sigma 1)$ attitude $\left(05^{\circ} / 322^{\circ}\right)$ were recognized in this station. This stress state is compatible with NW-SE stress in traverse 1/ station 2 Figures-(10 and 11). Individual (ac) and (bc) tension sets and (h0l) acute about (c) shear system were also recorded in this station.

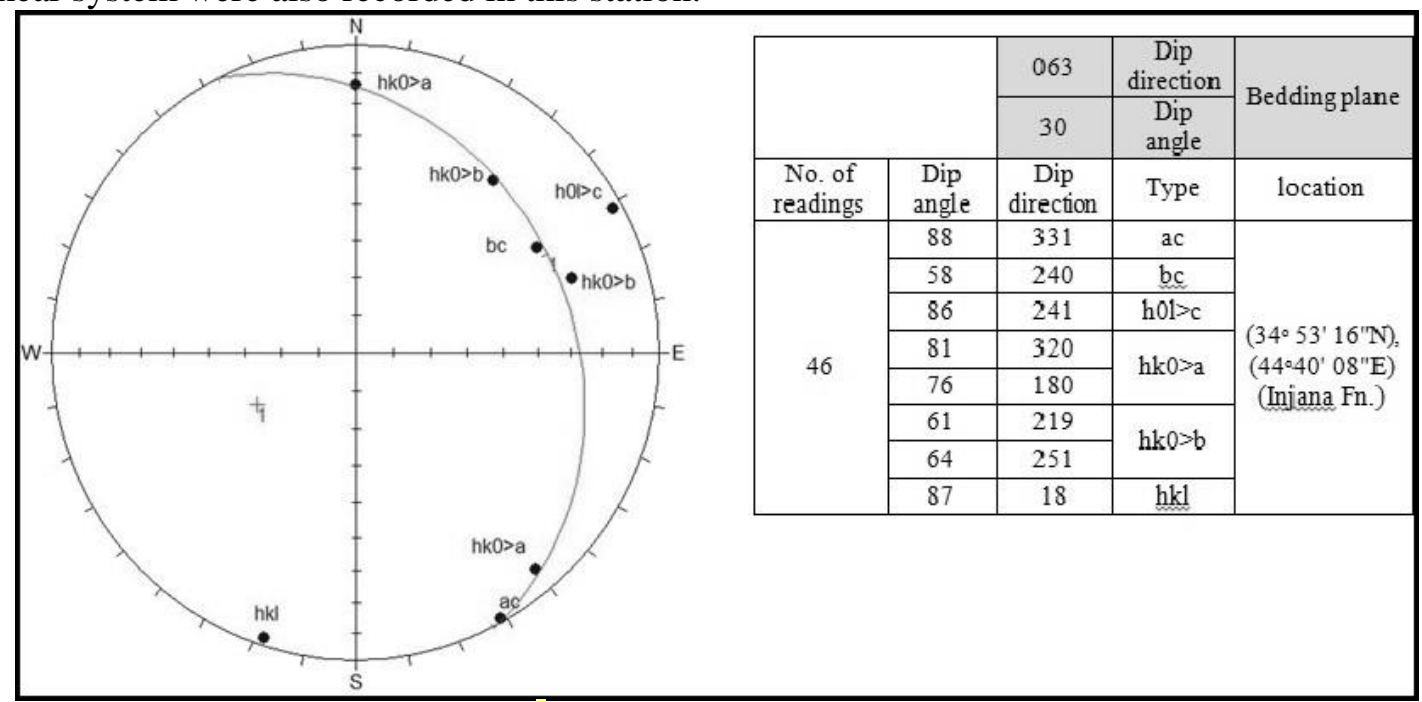

Figure 10-Stereographic projection of joint poles in traverse 1/ station 3.

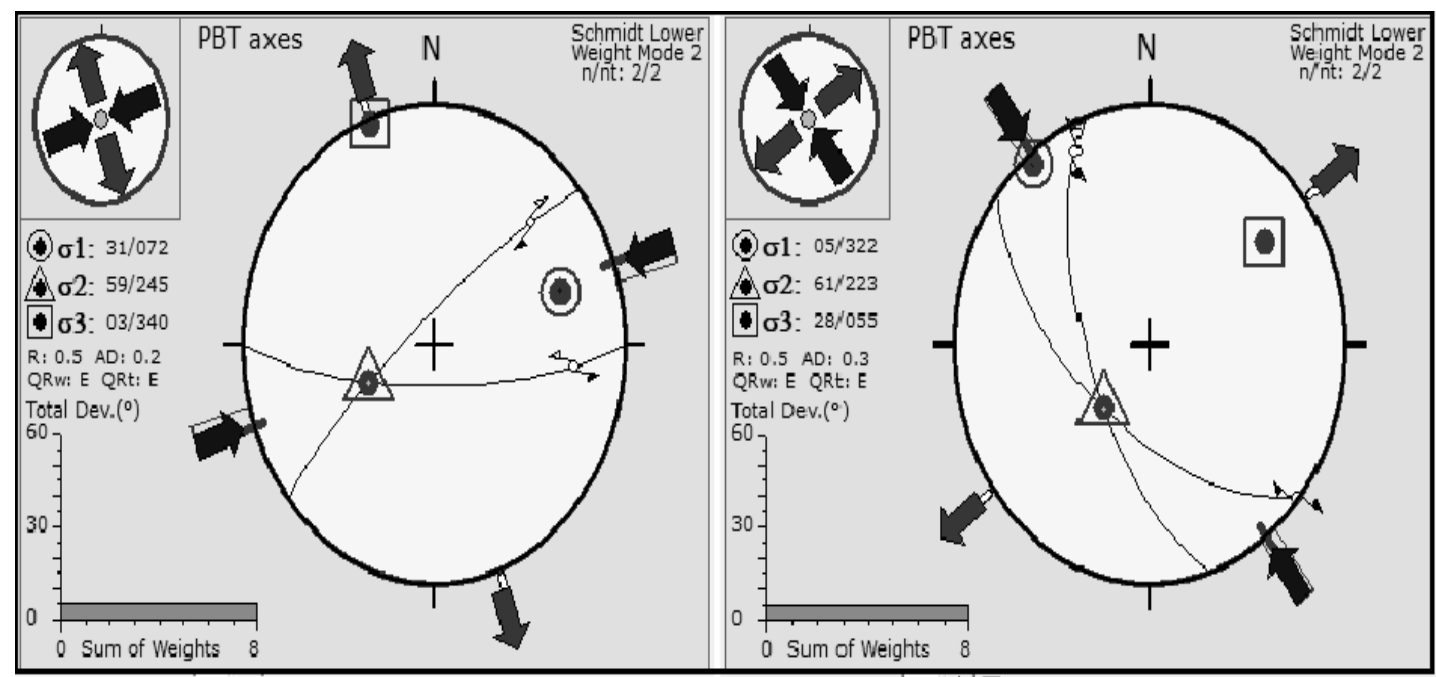

Figure 11 A- paleostress analysis from (hk0) acute about (a); B: paleostress analysis from (hk0) acute about (b) in traverse $1 /$ station 3 .

\section{Traverse 1/ station 4}

compressive stress from (hk0) acute about (a) axis shear systems with $(\sigma 1)$ attitude $\left(31^{\circ} / 064^{\circ}\right)$ and NW-SE compressive stress from (hk0) acute about (b) axis shear systems with $(\sigma 1)$ attitude $\left(02^{\circ} / 340^{\circ}\right)$ were recognized in this station. This stress state is compatible with NE-SW stress in traverse 1/ station 3 and NW-SE stress in traverse 1/ stations $2 \& 3$ (Figures 12 and 13). Individual (ac) and (bc) tension sets were recorded in this station as well. 


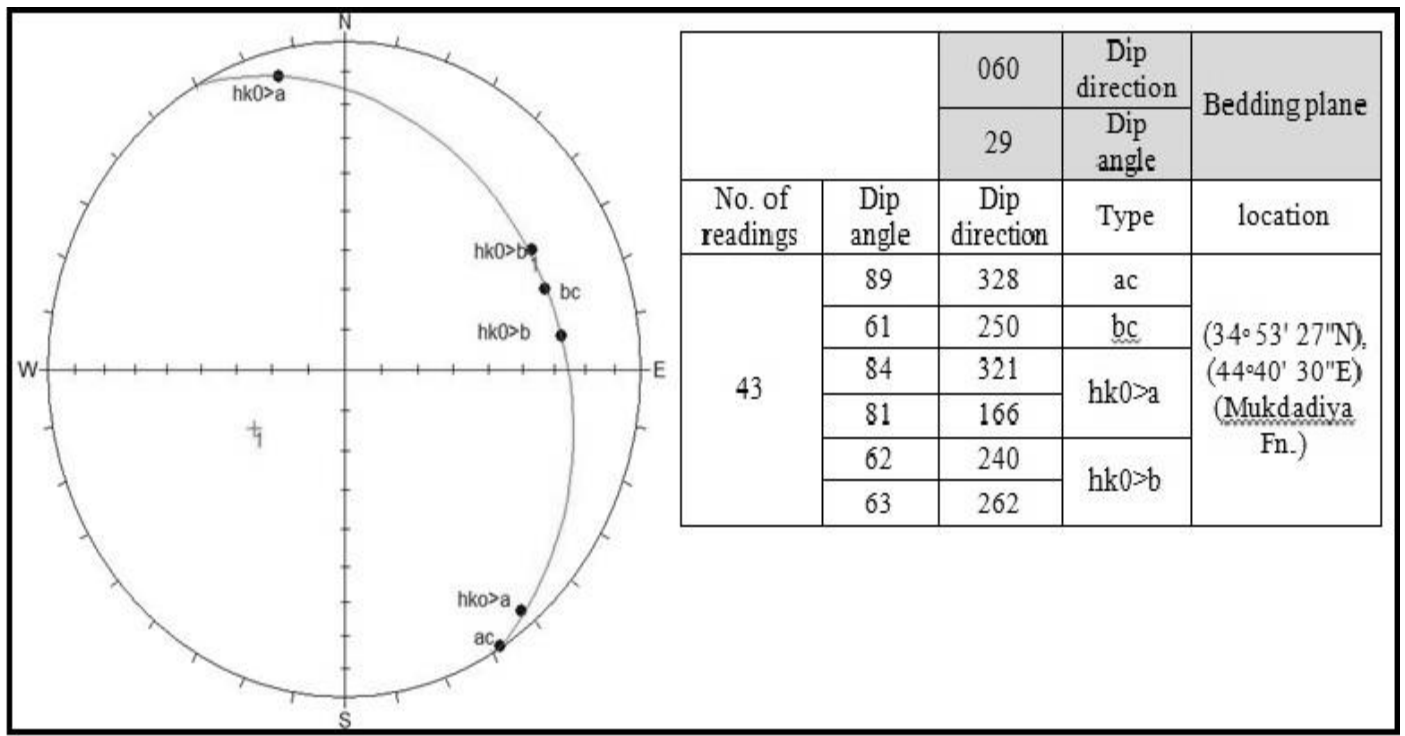

Figure 12-Stratigraphic projection of joint poles in traverse 1/ station 4.

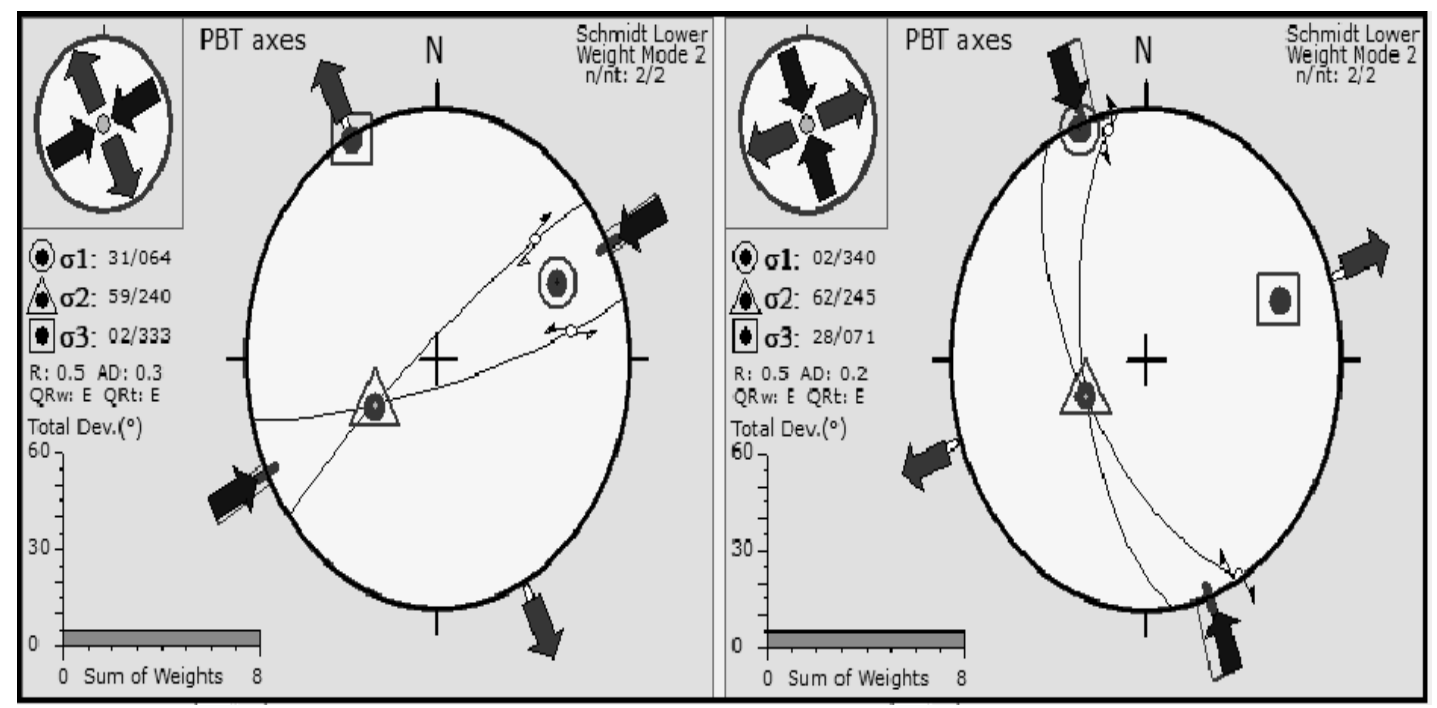

Figure 13 A-paleostress analysis from (hk0) acute about (a); B: paleostress analysis from (hk0) acute about (b) in traverse $1 /$ station 4.

\section{Traverse 1/ station 5}

NE-SW compressive stress from (hk0) acute about (a) axis shear systems with (б1) attitude $\left(38^{\circ} / 060^{\circ}\right)$ and NW-SE compressive stress from (hk0) acute about (b) axis shear systems with $(\sigma 1)$ attitude $\left(02^{\circ} / 140^{\circ}\right)$ were recognized in this station. This stress state is compatible with NE-SW stress in traverse 1/ stations $3 \& 4$ and NW-SE stress in traverse 1/ stations 2, $3 \& 4$ (Figures-(14 and 15). Individual (ac) and (bc) tension sets as well as (h0l) acute about (c) system were also recorded in this station. 


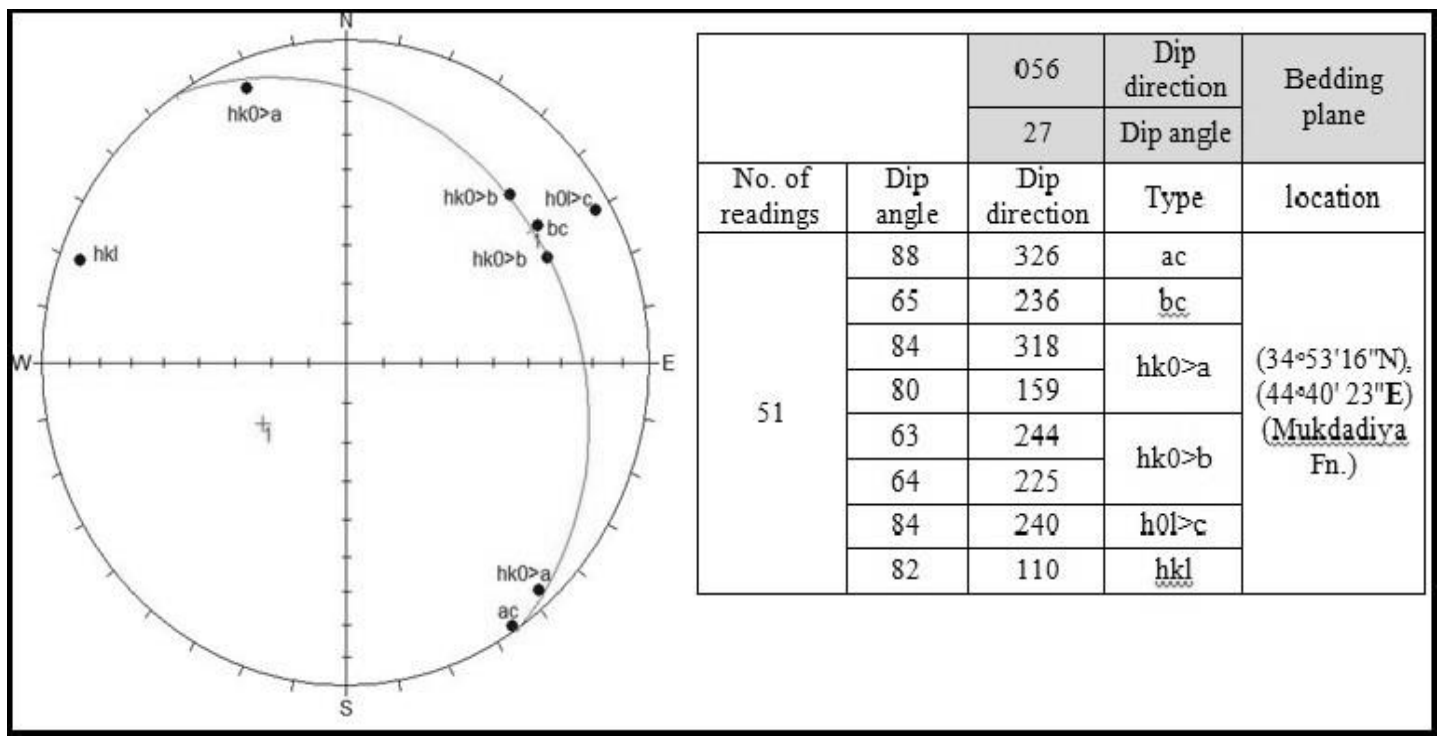

Figure 14-Stratigraphic projection of joint poles in traverse 1/ station 5.

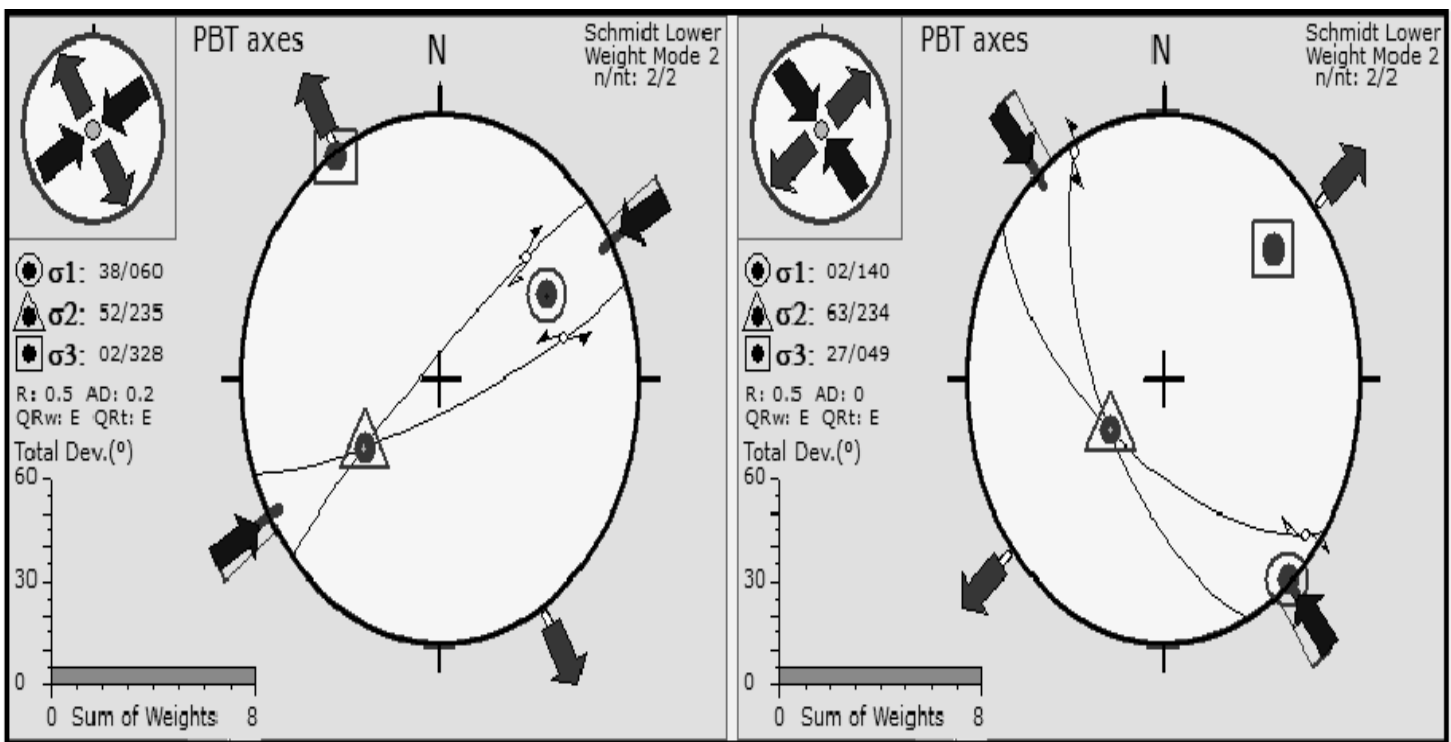

Figure 15 A-paleostress analysis from (hk0) acute about (a); B: paleostress analysis from (hk0) acute about (b) in traverse $1 /$ station 5 .

\section{Traverse 2/ station 1}

As shown in Figure-16, the following shear systems were recognized: (hk0) acute about (a) axis , (hk0) acute about (b) axis, (h0l) acute about (c) axis, and (0kl) acute about (c) axis. The paleostresses which were analyzed from the shear joint systems are as described below.

\section{Compressive stress}

a) NE-SW compressive stress from (hk0) acute about (a) axis with $(\sigma 1)$ attitudes $\left(27^{\circ} / 048^{\circ}\right.$ ), normal to sub-normal to the general trend of the major anticline. This stress state is compatible with NE-SW stress in traverse $1 /$ stations $3,4 \& 5$ and it seems as being responsible for the initial folding of the anticline (Figure-17A).

b) NW-SE compressive stress from (hk0) acute about (b) with $(\sigma 1)$ attitudes $\left(04^{\circ} / 132^{\circ}\right)$ (Figure17 B). This stress state is compatible with NW-SE stress in traverse 1/ stations $2,3,4 \& 5$.

\section{Extensional stress}

a) NE-SW extensional stress from (h0l) acute about (c) axis with sub horizontal $(\sigma 3)$ attitude $\left(02^{\circ} / 047^{\circ}\right)$ associated with the final uplifting of the major fold (Figure $17 \mathrm{C}$ ).

b) NW-SE extensional stress from $(0 \mathrm{kl})$ acute about $(\mathrm{c})$ with $(\sigma 3)$ attitudes $\left(03^{\circ} / 318^{\circ}\right)$ (Figure- 17 
D). This stress state is compatible with NW-SE stress in traverse 1/ station 1. Individual (ac) and (bc) tension sets were recorded in this station as well.

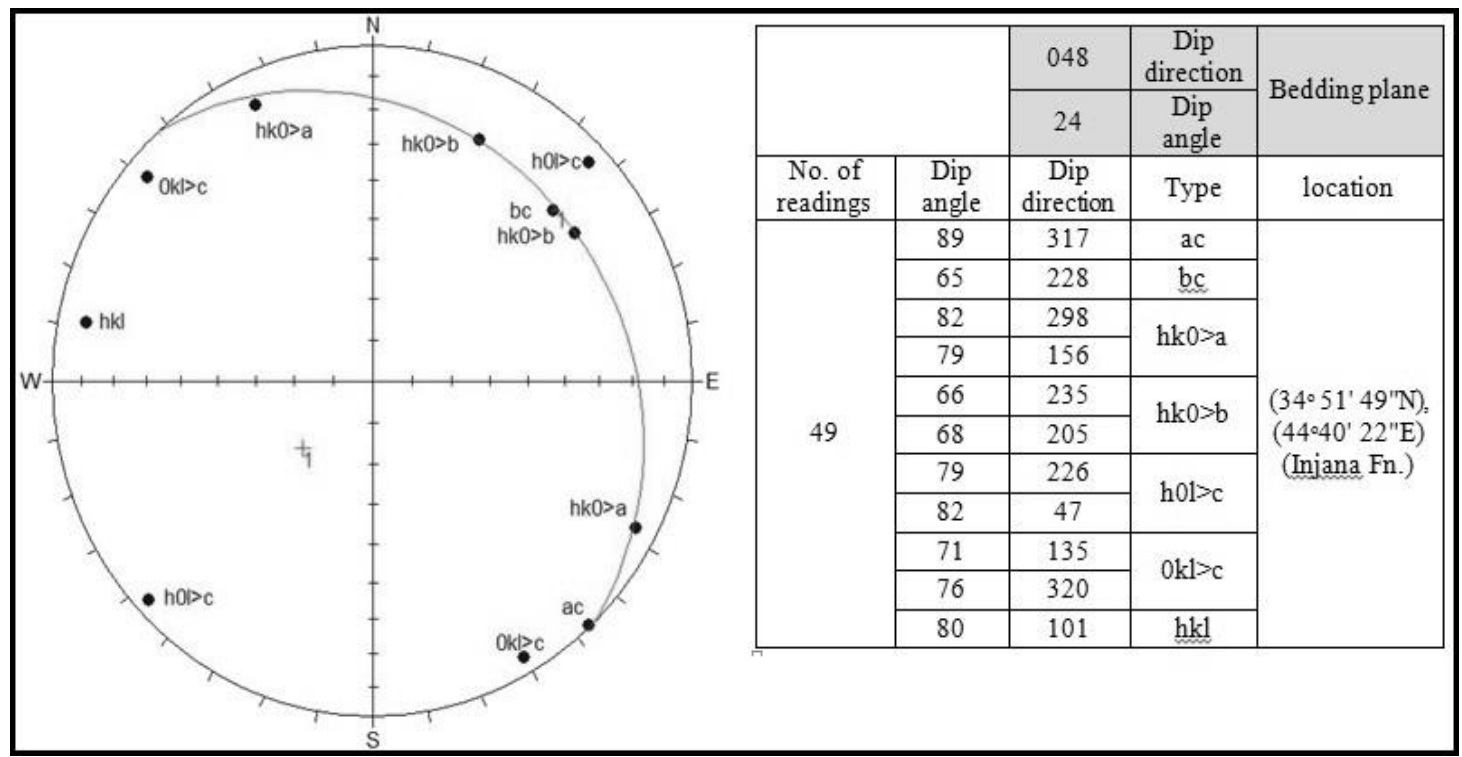

Figure 16-Stratigraphic projection of joint poles in traverse 2/ station 1.

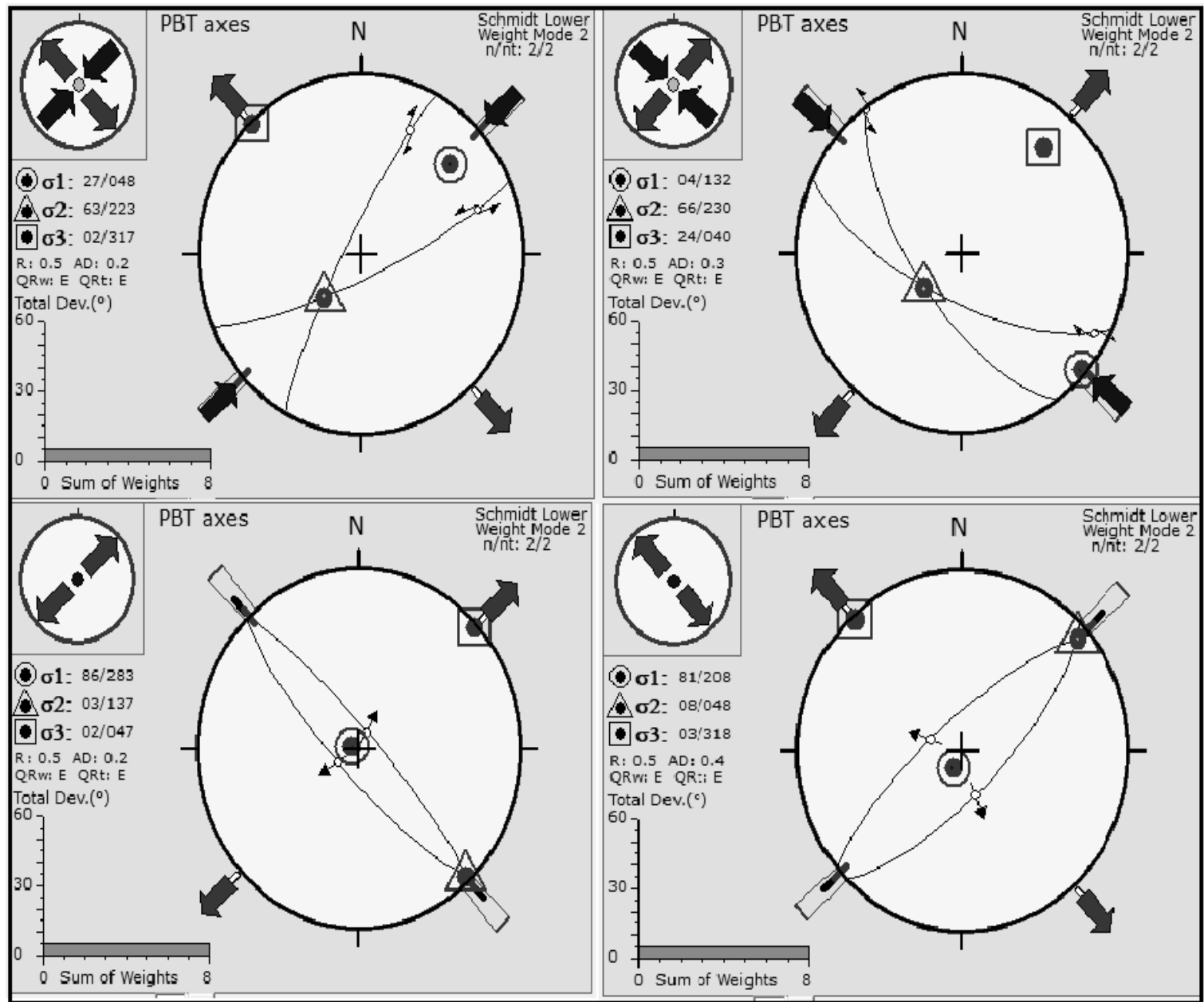

Figure $17 \mathrm{~A}$ - paleostress analysis from (hk0) acute about (a); B: paleostress analysis from (hk0) acute about (b); C: paleostress analysis from (h0l) acute about (c); D: paleostress analysis from (0kl) acute about (c) in traverse $2 /$ station 1 . 


\section{Traverse 2/ station 2}

NE-SW compressive stress from (hk0) acute about (a) axis shear system with $(\sigma 1)$ attitude $\left(23^{\circ} / 055^{\circ}\right)$ was recognized in this station (Figures- 18 and 19). Individual (hk0) acute about (a) axis and (h0l) acute about (c) axis systems as well as (ac) and (bc) sets were also recognized in this station.

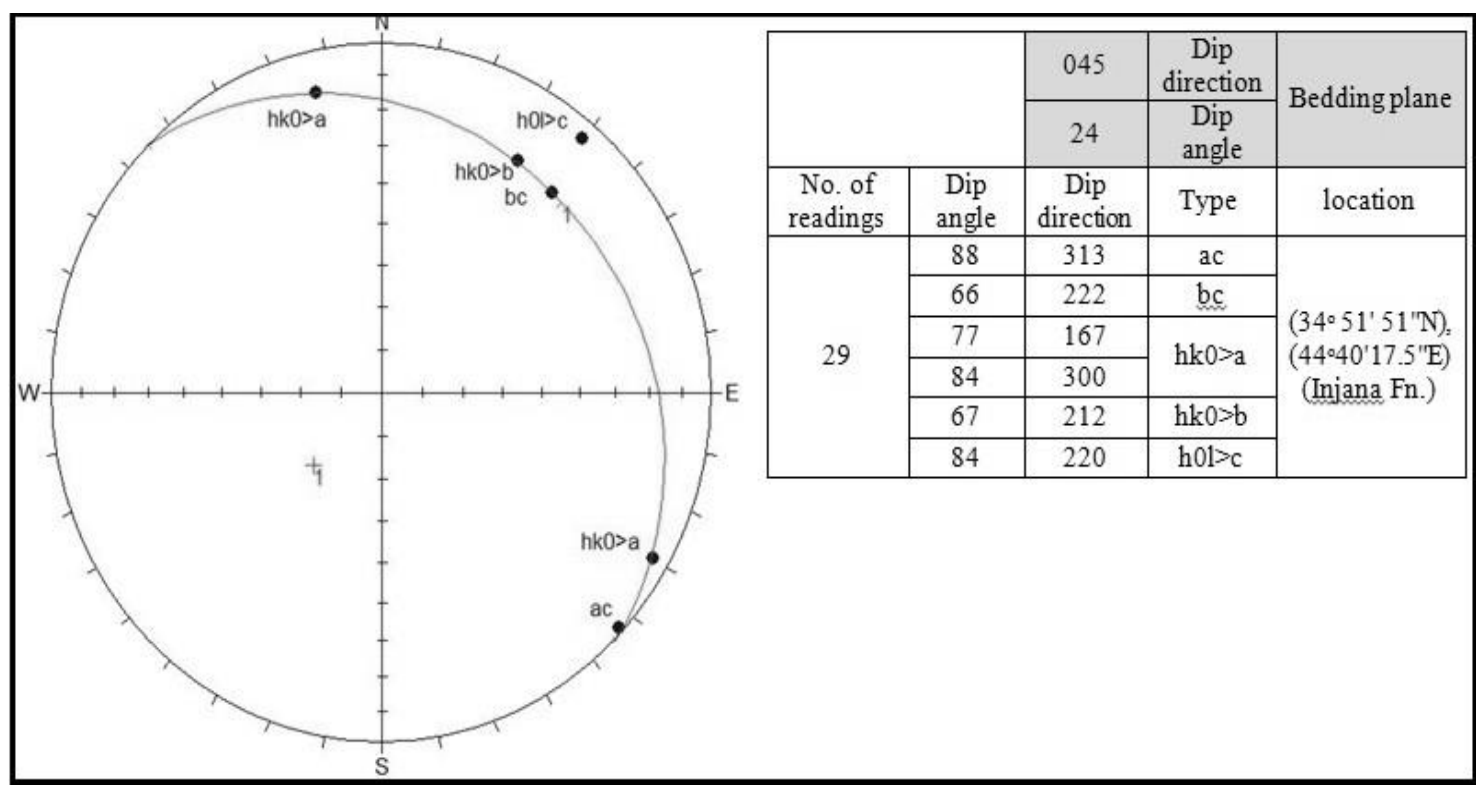

Figure 18-Stratigraphic projection of joint poles in traverse 2/ station 2.

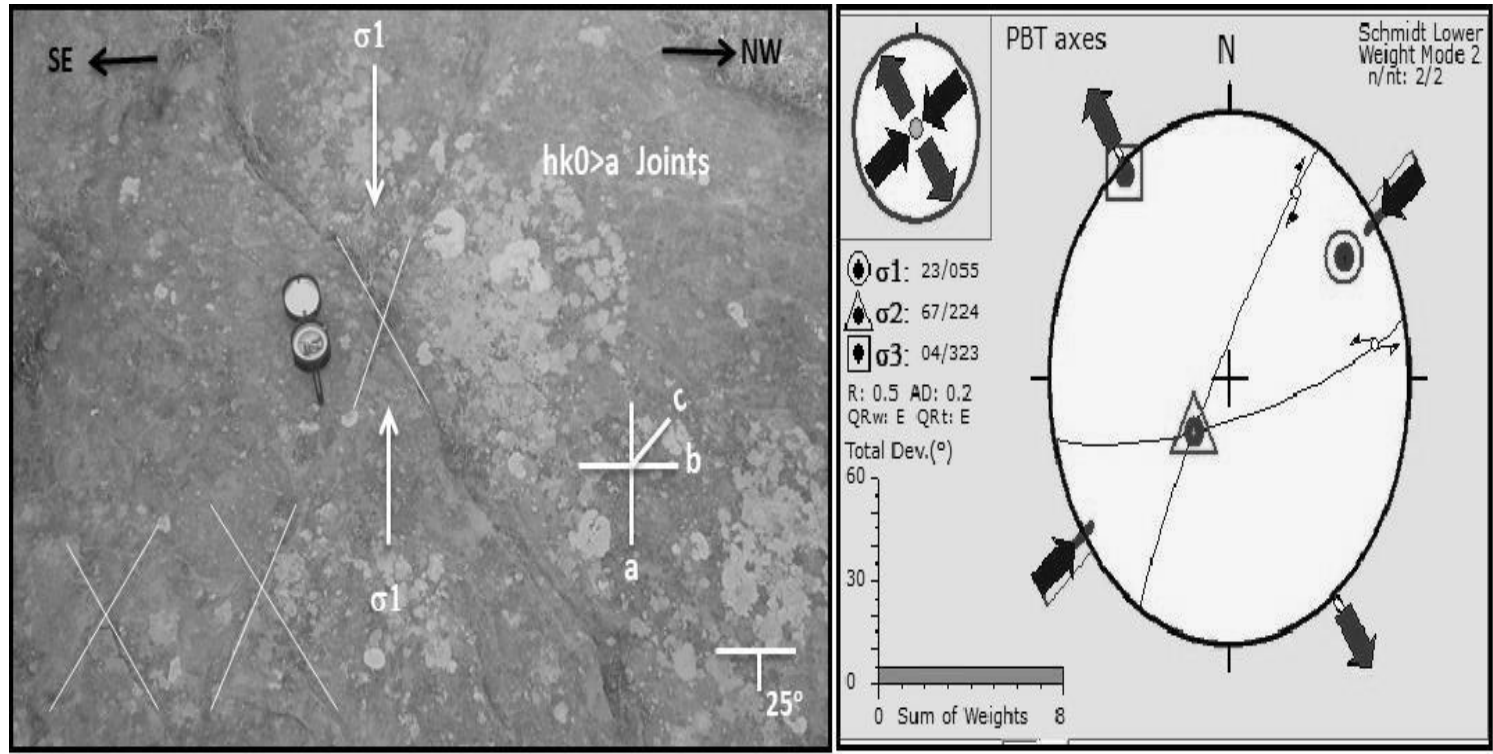

Figure 19 A-field photo of (hk0) acute about (a); B: paleostress analysis from (hk0) acute about (a) in traverse $2 /$ station 2 .

\section{Traverse 2/ station 3}

NE-SW compressive stress from (hk0) acute about (a) axis shear systems with $(\sigma 1)$ attitude $\left(25^{\circ} / 052^{\circ}\right)$ and NW- SE extensional stress from (0kl) acute about (c) axis shear systems with $(\sigma 3)$ attitude $\left(01^{\circ} / 317^{\circ}\right)$ were recognized in this station (Figures- 20 and 21). Individual (ac) and (bc) tension sets as well as (h0l) acute about (c) axis system were recorded in this station. 


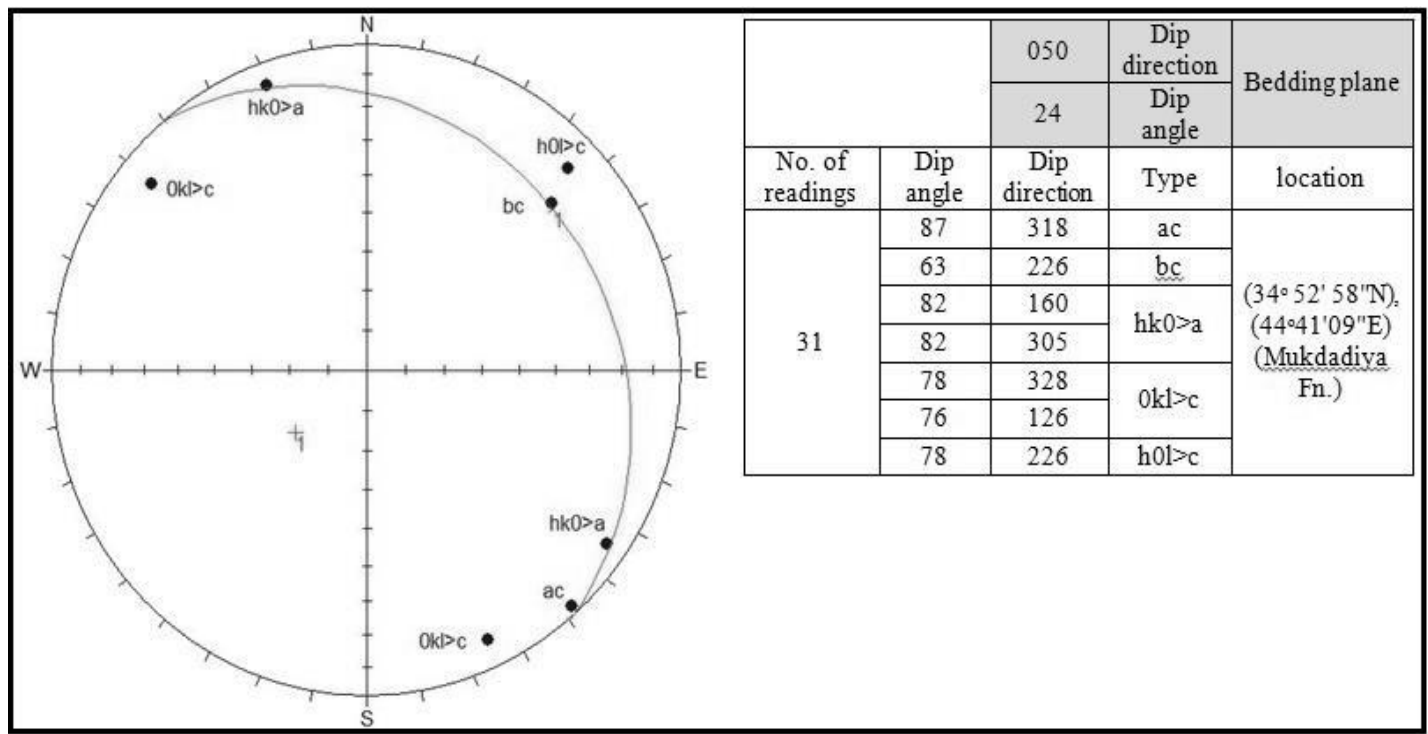

Figure 20-Stratigraphic projection of joint poles in traverse $2 /$ station 3.

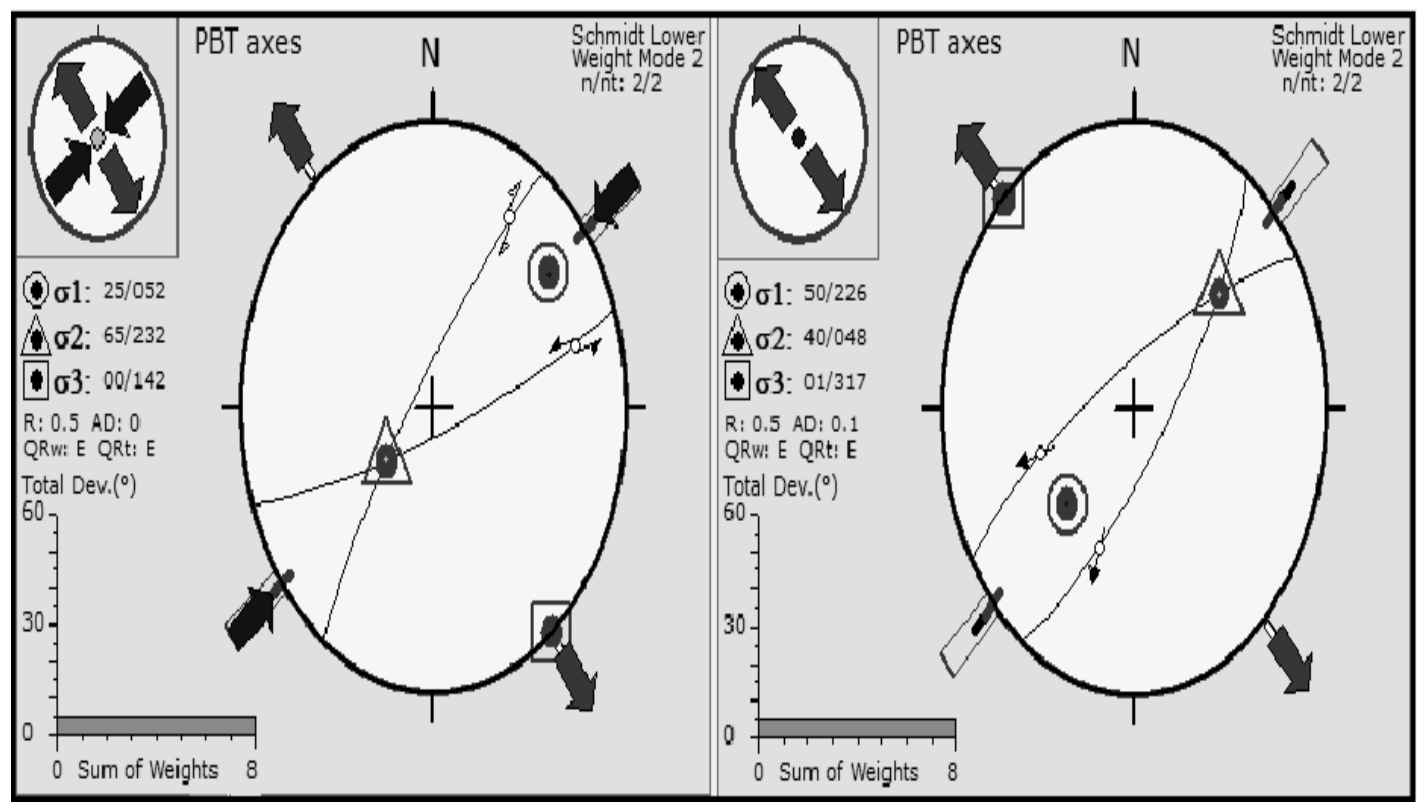

Figure 21 A-paleostress analysis from (hk0) acute about (a); B: paleostress analysis from (0kl) acute about (c) in traverse $2 /$ station 3 .

\section{Traverse 2/ station 4}

NE-SW compressive stress from (hk0) acute about (a) axis shear systems with $(\sigma 1)$ attitude $\left(26^{\circ} / 056^{\circ}\right)$ and NE- SW extensional stress from (h01) acute about (c) axis shear systems with $(\sigma 3)$ attitude $\left(03^{\circ} / 049^{\circ}\right)$ were recognized in this station (Figures- 22 and 23). Individual (ac) and (bc) tension sets as well as (hk0) acute about (b) axis system were recorded in this station. 


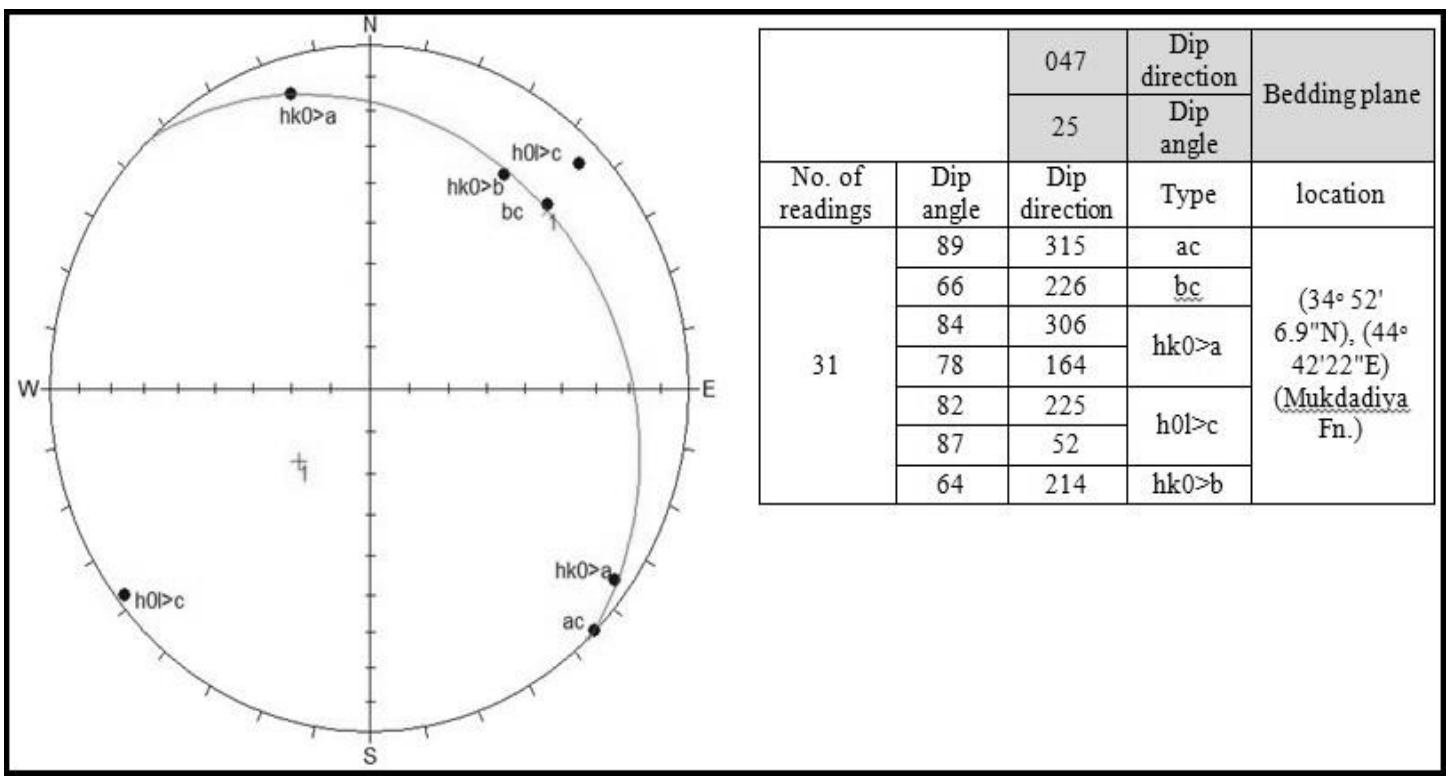

Figure 22-Stratigraphic projection of joint poles in traverse 2/ station 4 .

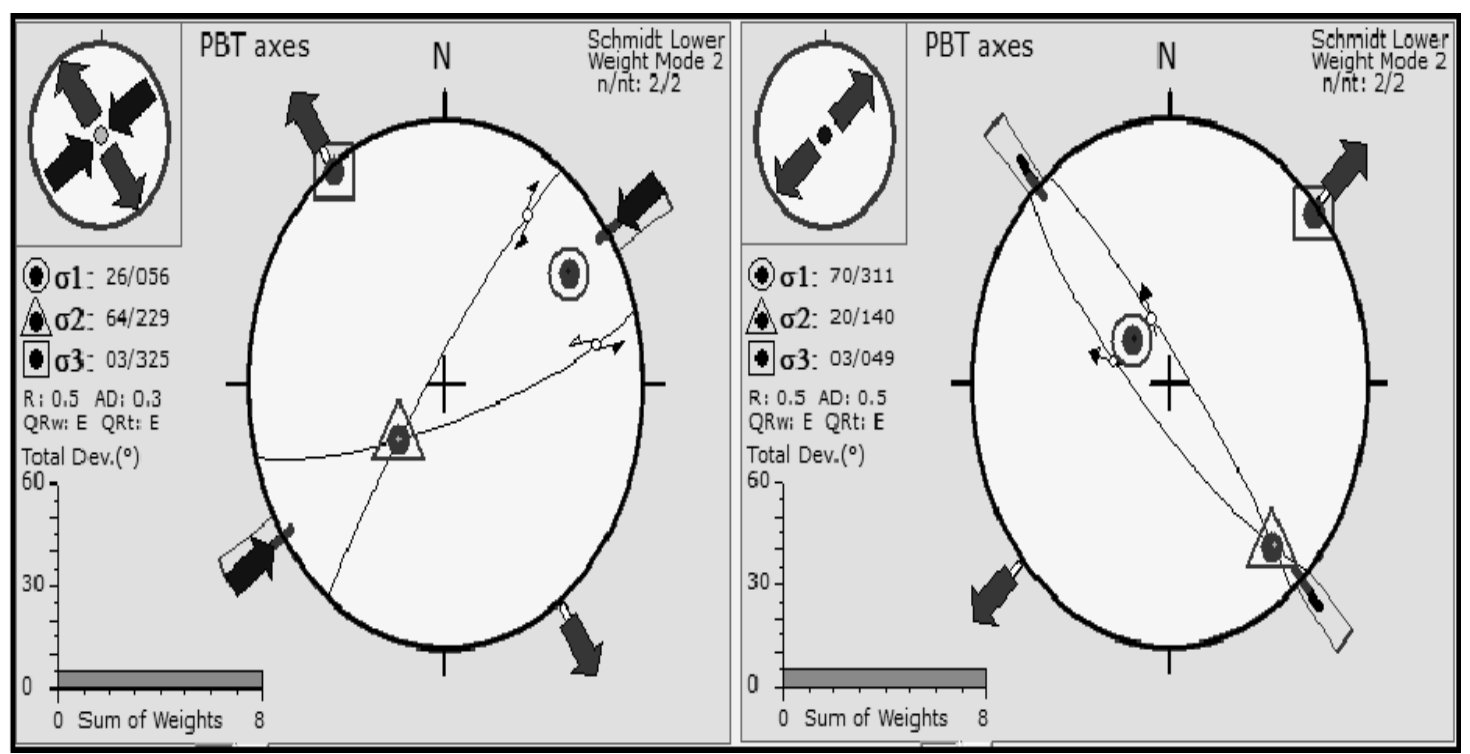

Figure 23 A- paleostress analysis from (hk0) acute about (a); B: paleostress analysis from (h0l) acute about (c) in traverse $2 /$ station 4.

\section{Traverse 3/ station 1}

NW-SE compressive stress from (hk0) acute about (b) axis shear system with $(\sigma 1)$ attitude $\left(02^{\circ} / 323^{\circ}\right.$ ) was recognized in this station (Figures- 24 and (Figure- $25 \mathrm{~B}$ ). Individual (hk0) acute about (a) axis, (h0l) acute about (c) axis, (0kl) acute about (c) axis systems as well as (ac) and (bc) sets were recognized in this station. Figure- 25 A shows a field photo for (h0l) acute about (c) axis system. 


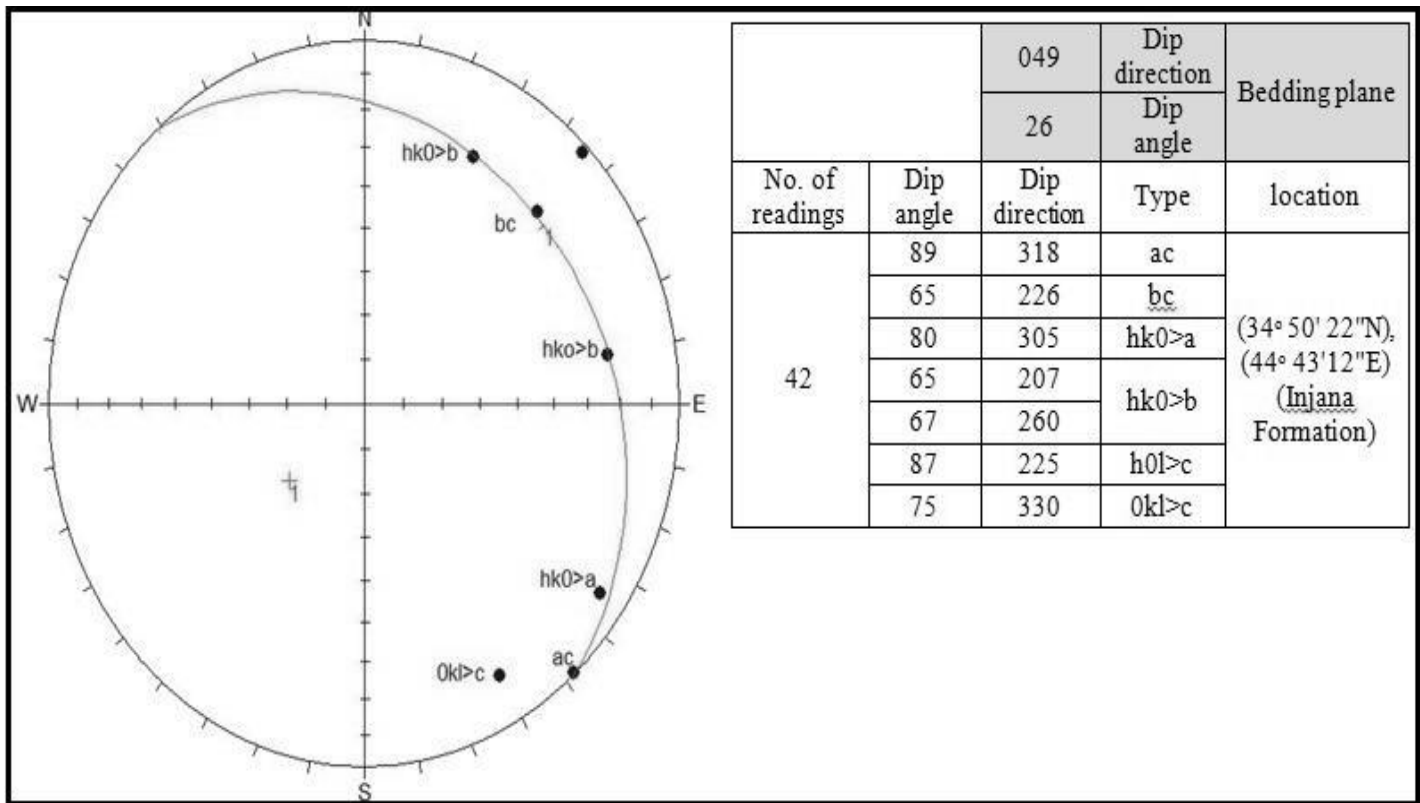

Figure 24-Stratigraphic projection of joint poles in traverse 3/ station 1.
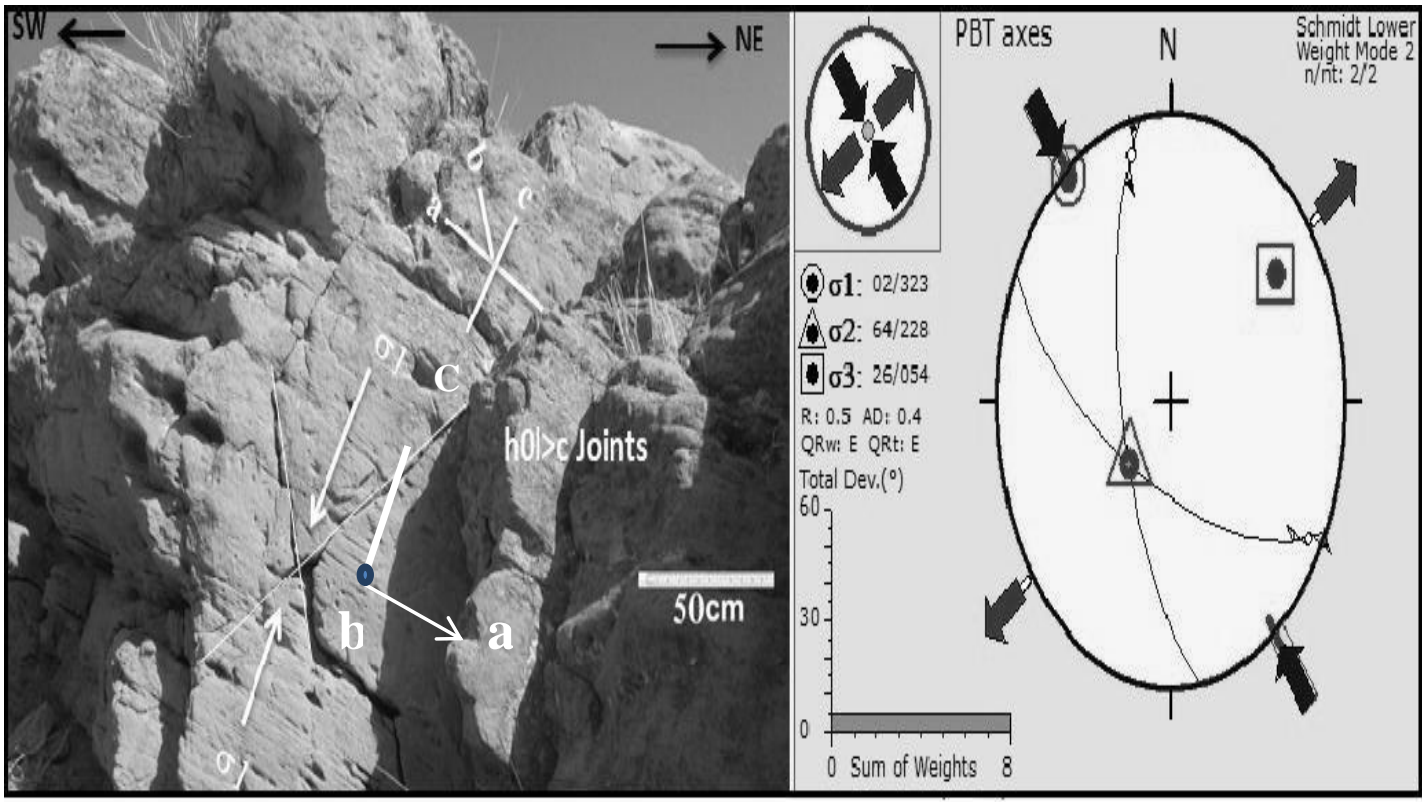

Figure 25 A-field photo of (h0l) acute about (c); B: paleostress analysis from (hk0) acute about (b) in traverse $3 /$ station 1 .

\section{Traverse 3/ station 2}

As shown in Figure-26, the following shear systems were recognized: (hk0) acute about (a) axis , (hk0) acute about (b) axis, and (0kl) acute about (c) axis. The paleostresses which were analyzed from shear joint systems are described below

\section{Compressive stress}

a) NE-SW compressive stress from (hk0) acute about (a) axis with (б1) attitudes $\left(22^{\circ} / 050^{\circ}\right)$, normal to sub-normal to the general trend of the major anticline (Figure- $27 \mathrm{~A}$ ).

b) NW-SE compressive stress from (hk0) acute about (b) with (б1) attitudes $\left(04^{\circ} / 319^{\circ}\right)$. (Figure$27 \mathrm{~B})$.

\section{Extensional stress}

Analyzed from (0kl) acute about (c) with ( $\boldsymbol{\sigma 3})$ attitudes $\left(02^{\circ} / 314^{\circ}\right)$ (Figure- $\left.27 \mathrm{C}\right)$. Individual (ac) and (bc) tension sets were recorded in this station as well. 


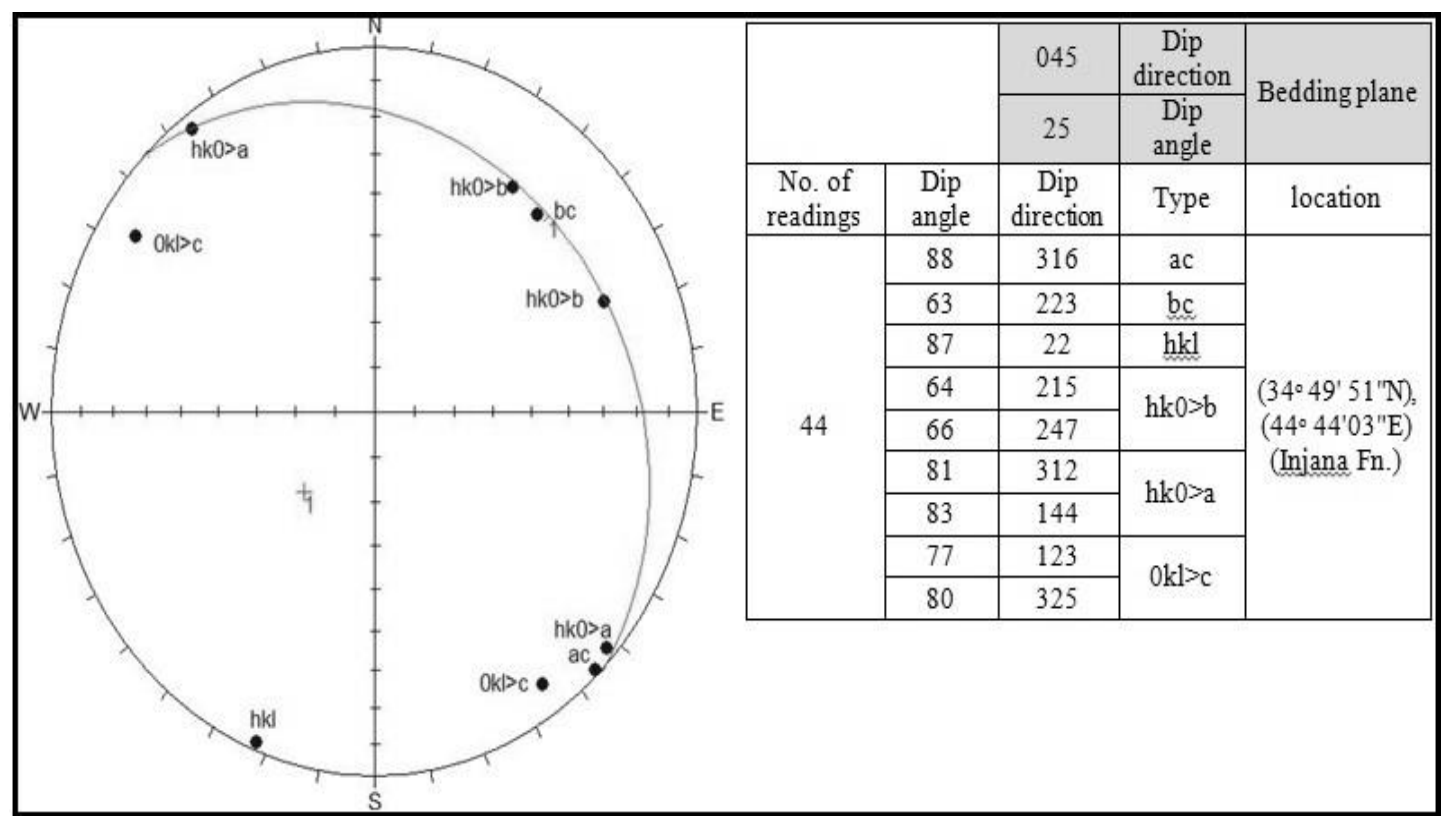

Figure 26-Stratigraphic projection of joint poles in traverse 3/ station 2.

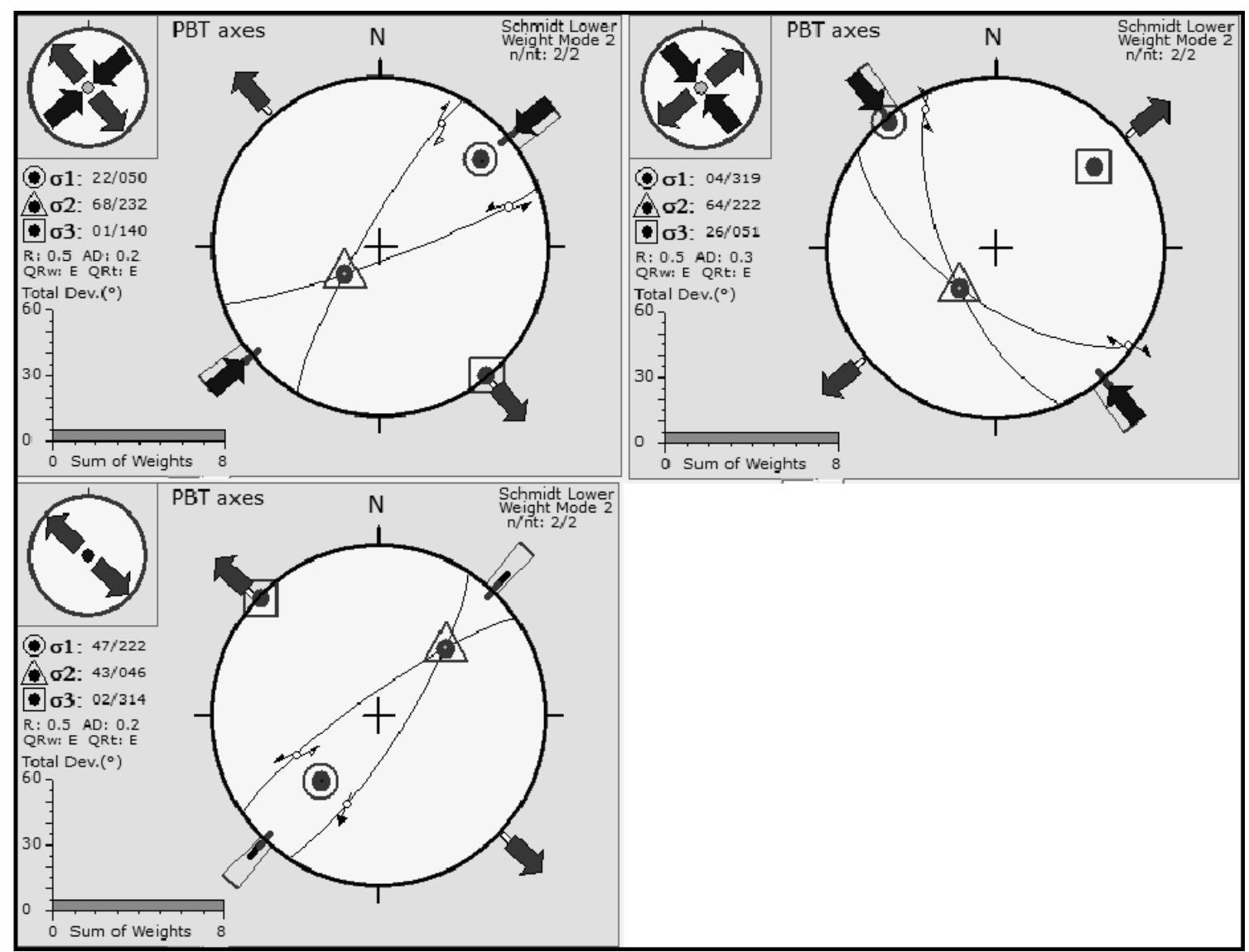

Figure 27 A-paleostress analysis from (hk0) acute about (a): B: paleostress analysis from (hk0) acute about (b); C: paleostress analysis from (0kl) acute about (c) in traverse 3/ station 2.

\section{Traverse 3/ station 3}

NW-SE compressive stress from (hk0) acute about (b) axis shear system with ( $\sigma 1)$ attitude $\left(03^{\circ} / 322^{\circ}\right)$ was recognized in this station (Figures- 28 and 29). Individual (h0l) acute about (c) axis and (0kl) acute about (c) axis systems as well as (ac) and (bc) sets were recognized in this station. 


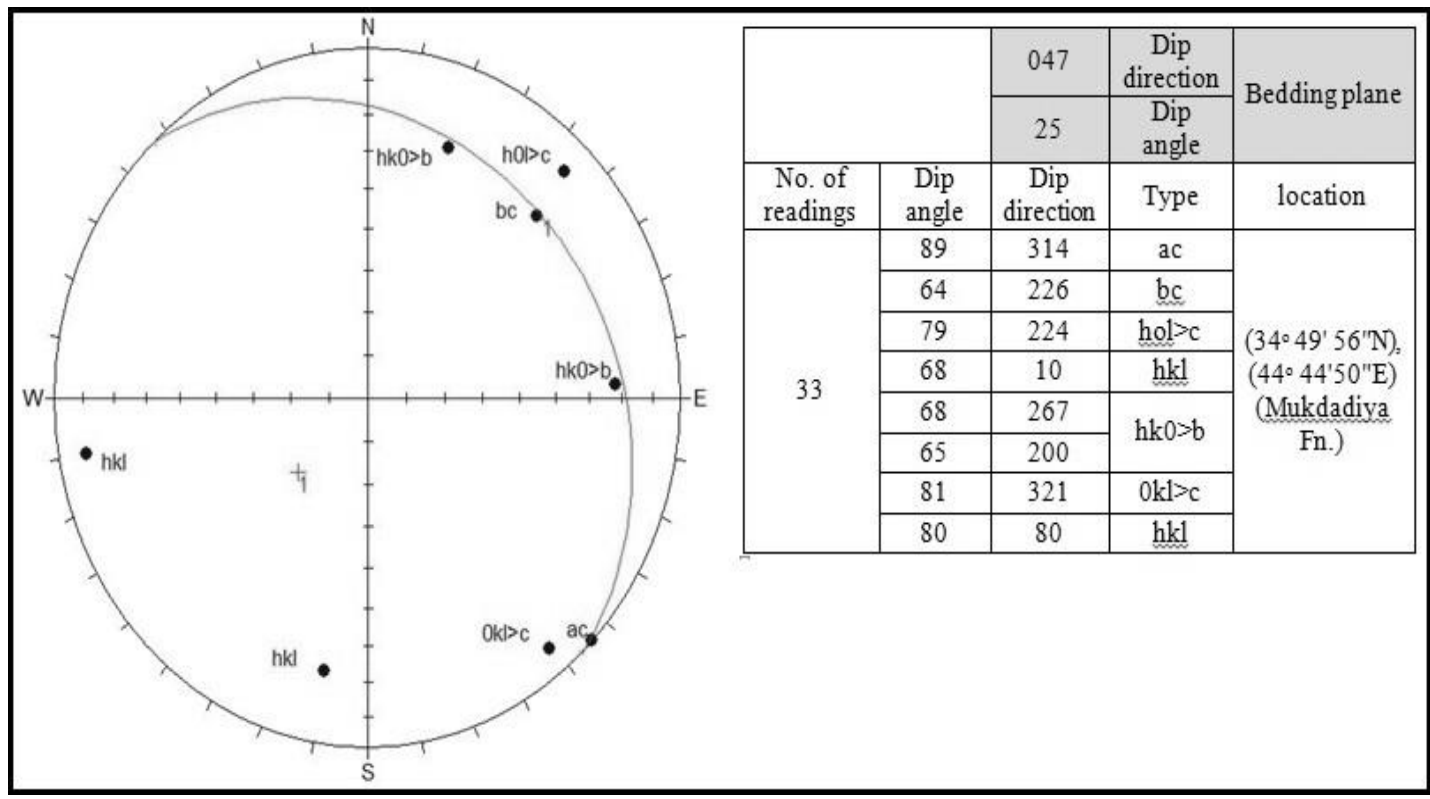

Figure 28-Stratigraphic projection of joint poles in traverse 3/ station 3.

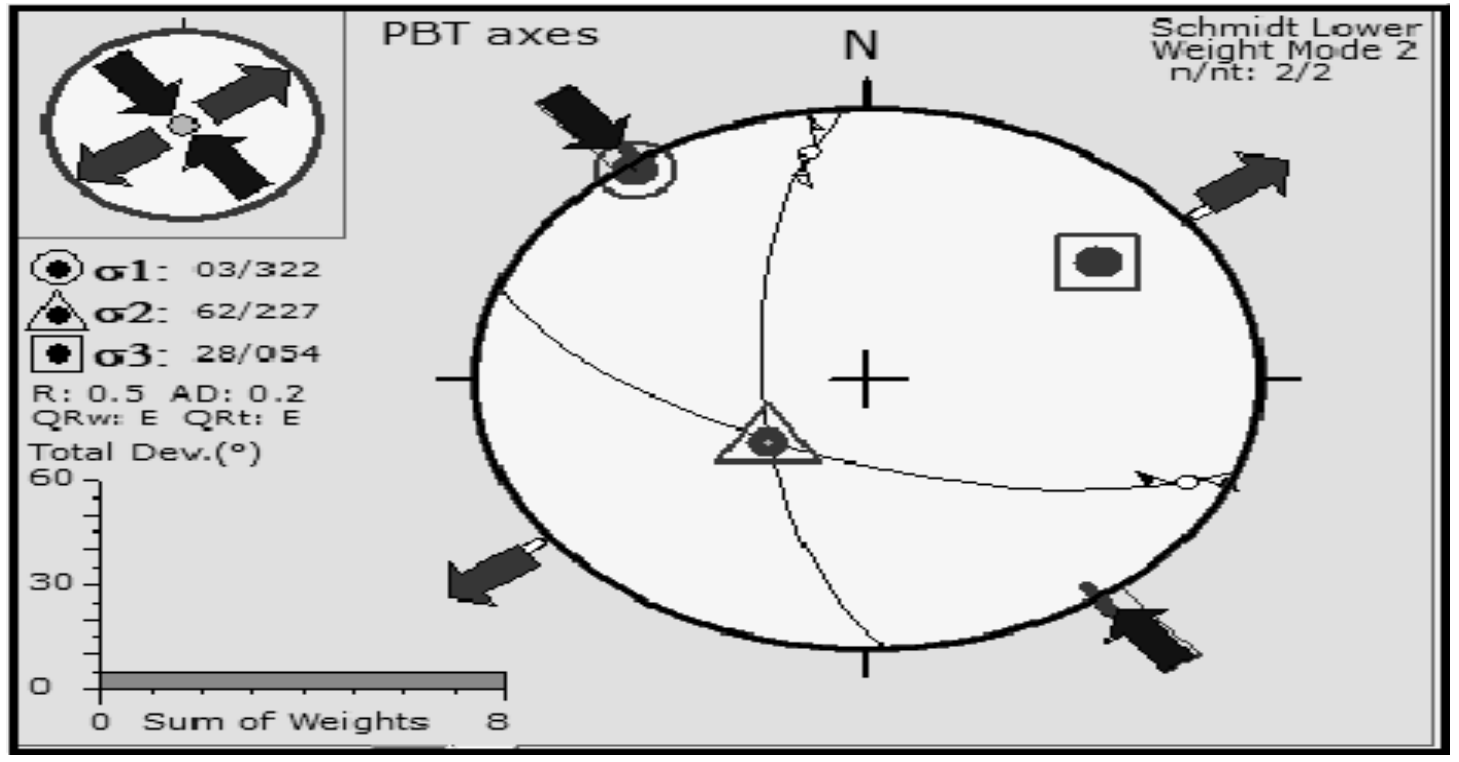

Figure 29-paleostress analysis from (hk0) acute about (b) in traverse 3/ station 3.

\section{Traverse 3/ station 4}

As shown in Figure-30, (hk0) acute about (b) axis and (0kl) acute about (c) axis shear systems were recognized. The paleostresses which were analyzed from the shear joint systems are described below.

\section{Compressive stress}

Analyzed stress from (hk0) acute about (b) with $(\sigma 1)$ attitudes $\left(04^{\circ} / 319^{\circ}\right)$ was found in this station (Figure-31 A).

\section{Extensional stress}

Analyzed from (0kl) acute about (c) with ( $\sigma 3)$ attitudes $\left(02^{\circ} / 314^{\circ}\right)$ (Figure- $\left.31 \mathrm{~B}\right)$. Individual (ac) and $(\mathrm{bc})$ tension sets were recorded in this station as well. 


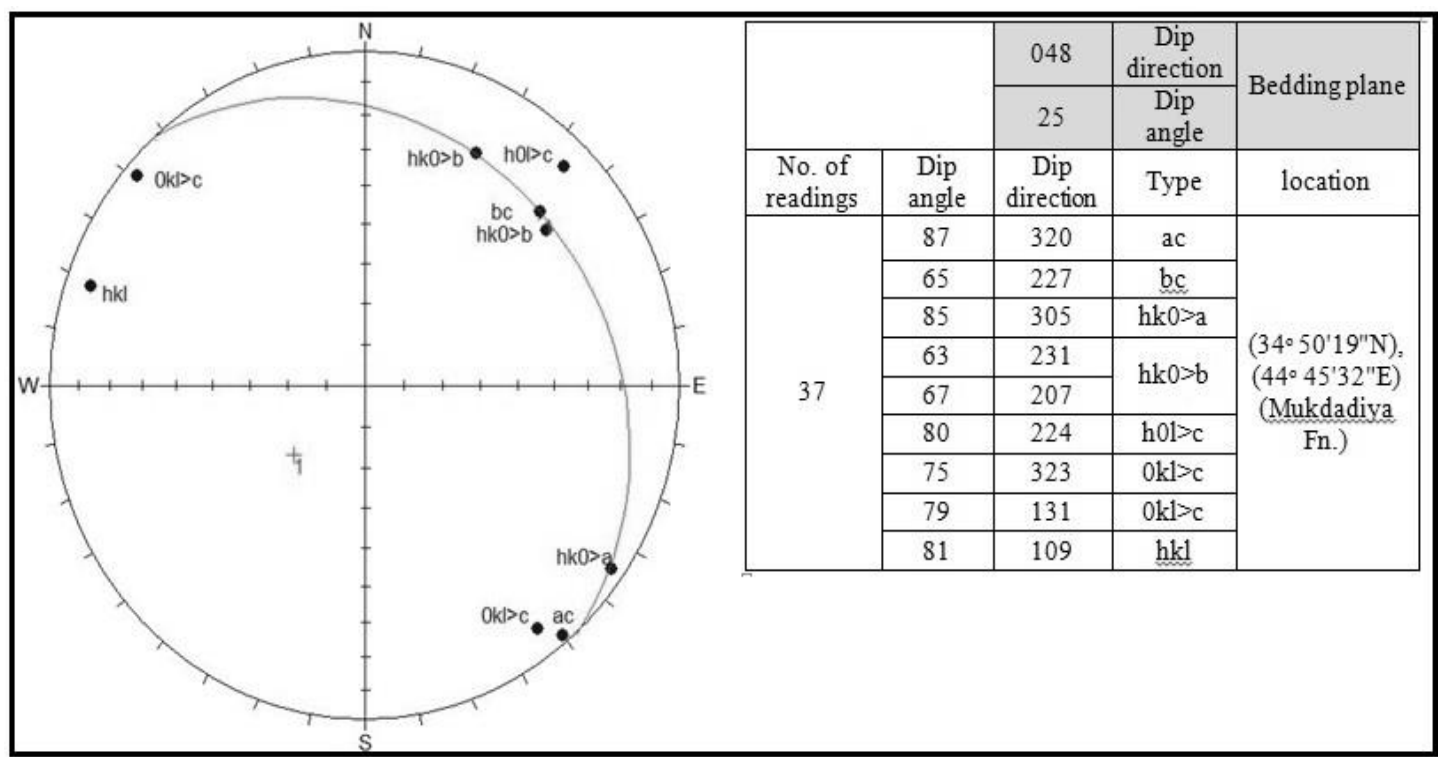

Figure 30-Stratigraphic projection of joint poles in traverse 3/ station 4

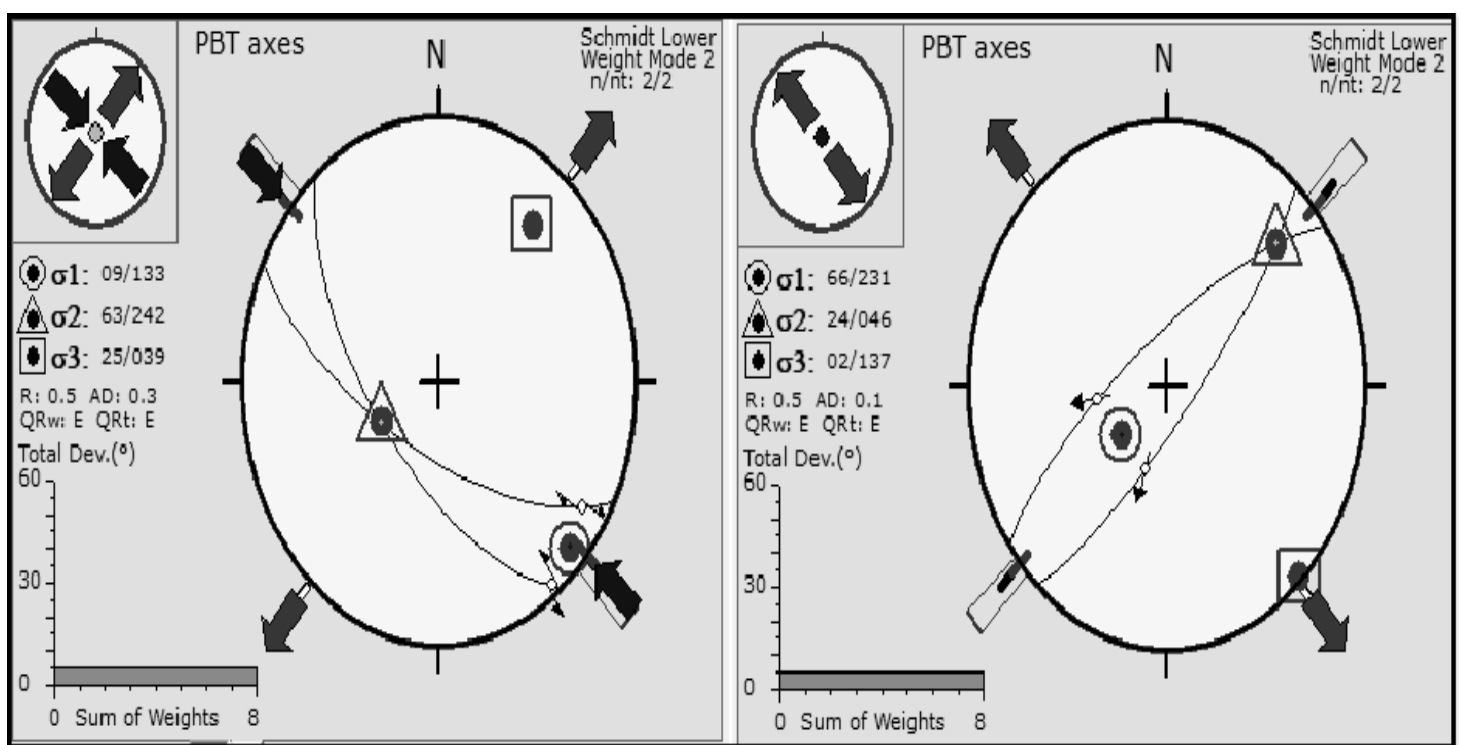

Figure 31 A-paleostress analysis from (hk0) acute about (b); B: paleostress analysis from (0kl) acute about (c) in traverse 3/ station 4.

\section{Traverse 4/ station 1}

NW-SE compressive stress from (hk0) acute about (b) axis shear system with ( $\sigma 1)$ attitude $\left(03^{\circ} / 130^{\circ}\right)$ was recognized in this station (Figures- 32 and 33). Individual (hk0) acute about (a) axis as well as (ac) and (bc) sets were recognized in this station. 


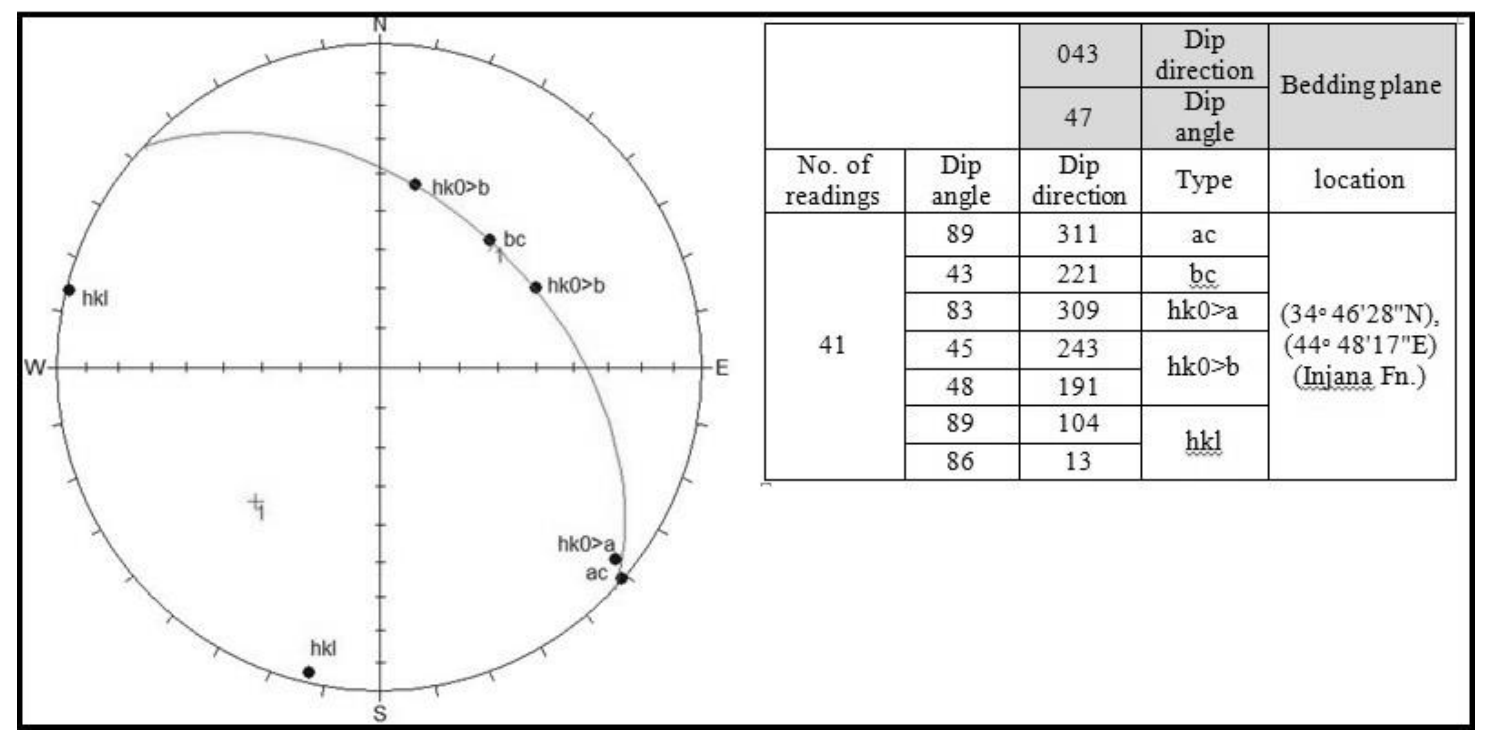

Figure 32-Stratigraphic projection of joint poles in traverse 4/ station 1.

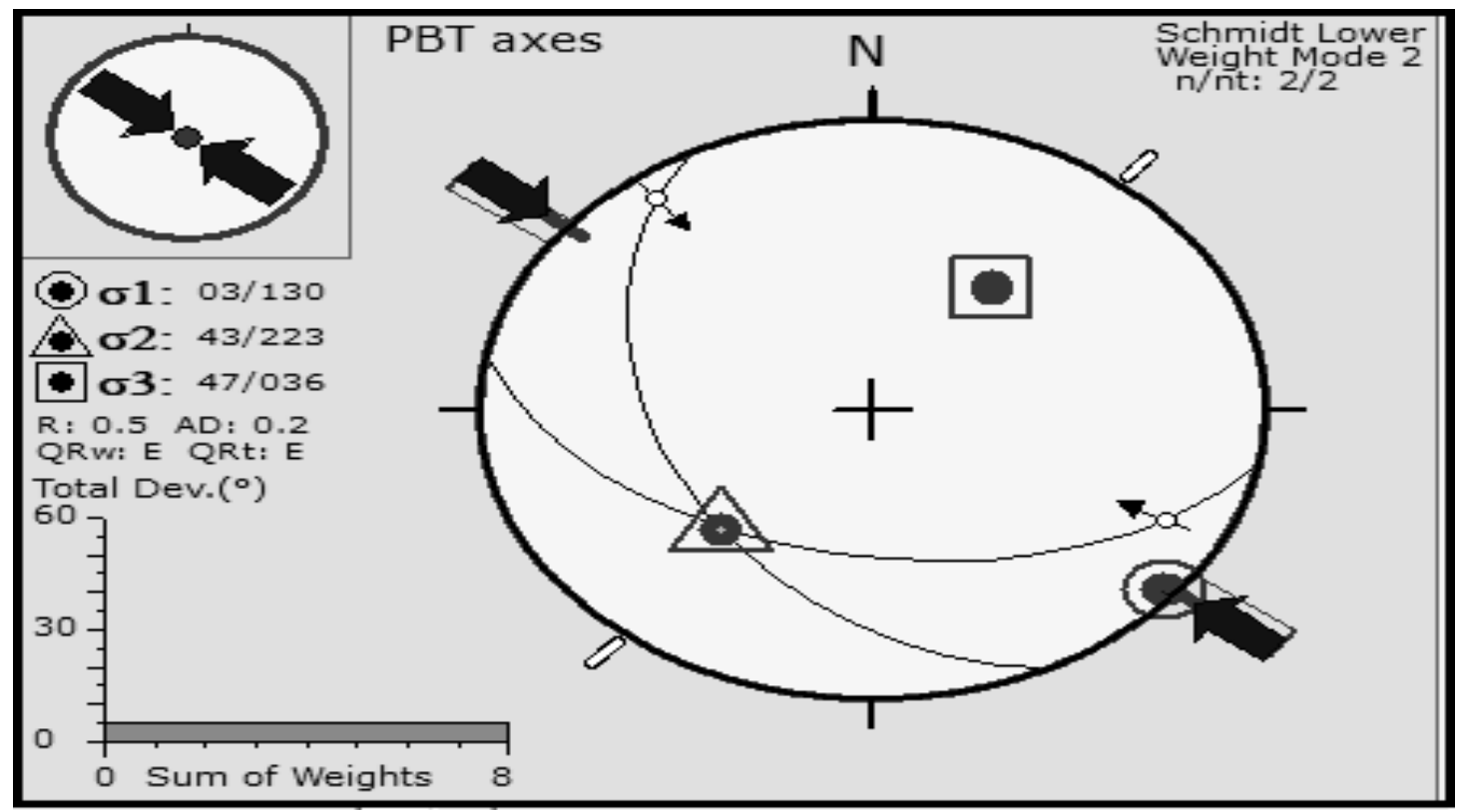

Figure 33-Paleostress analysis from (hk0) acute about (b) in traverse 4/ station 1.

\section{Traverse 4/ station 2}

No conjugate shear joint systems were observed in this station (Figure-34), whereas individual (hk0) acute about (a) axis, (hk0) acute about (b) axis, (h0l) acute about (c) axis systems, as well as (ac) and (bc) sets were recognized. 


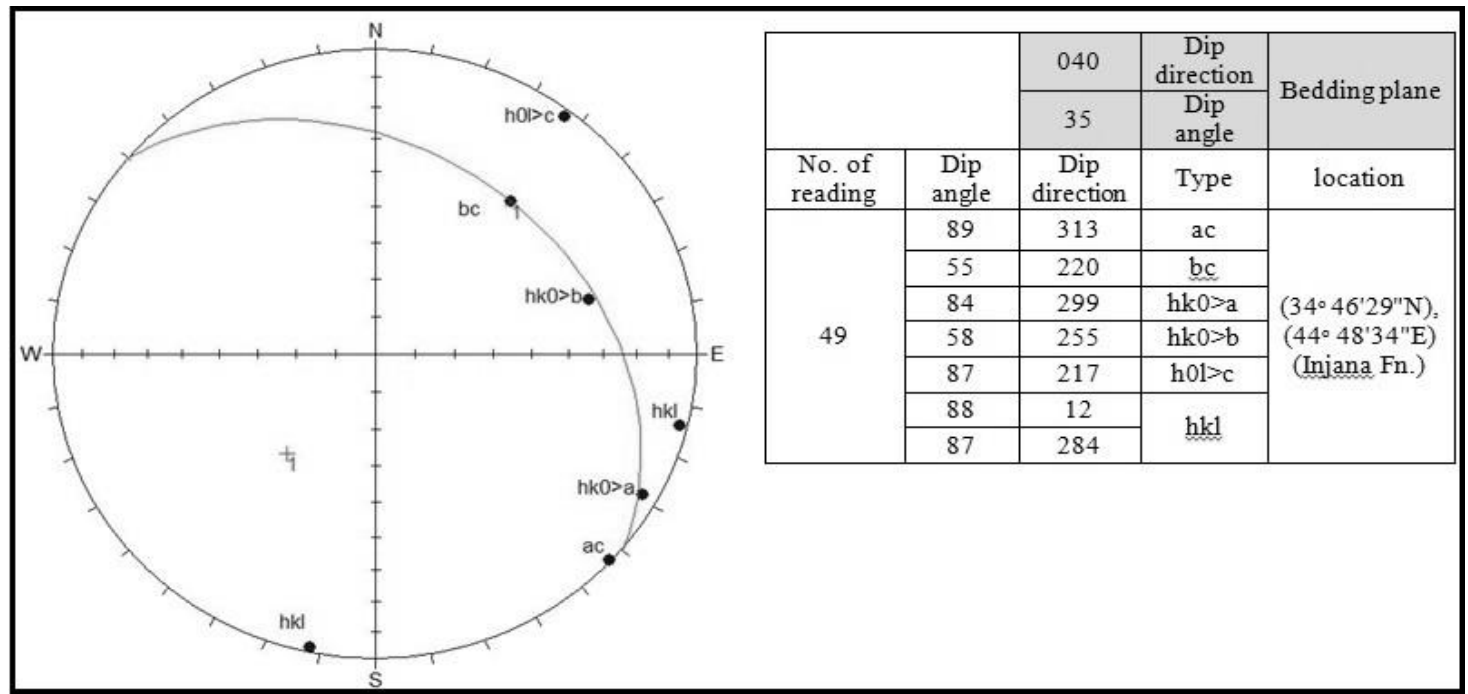

Figure 34-Stratigraphic projection of joint poles in traverse 4/ station 2.

\section{Traverse 4/ station 3}

NE-SW compressive stress from (hk0) acute about (a) axis shear system with ( $\sigma 1)$ attitude $\left(37^{\circ} / 044^{\circ}\right)$ was recognized in this station (Figures- 35 and 36). Individual (hk0) acute about (b) axis, (h0l) acute about (c) axis systems, as well as (ac) and (bc) sets were recognized in this station.

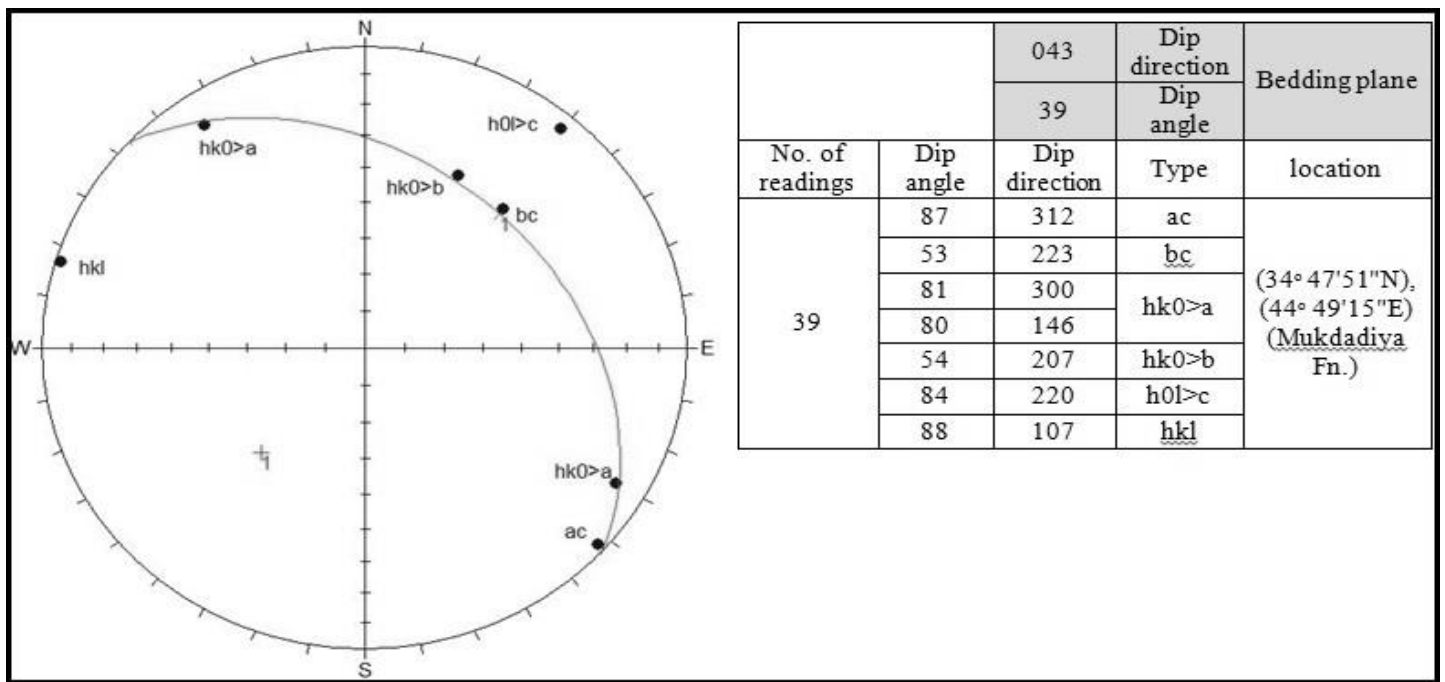

Figure 35-Stratigraphic projection of joint poles in traverse 4/ station 3 .

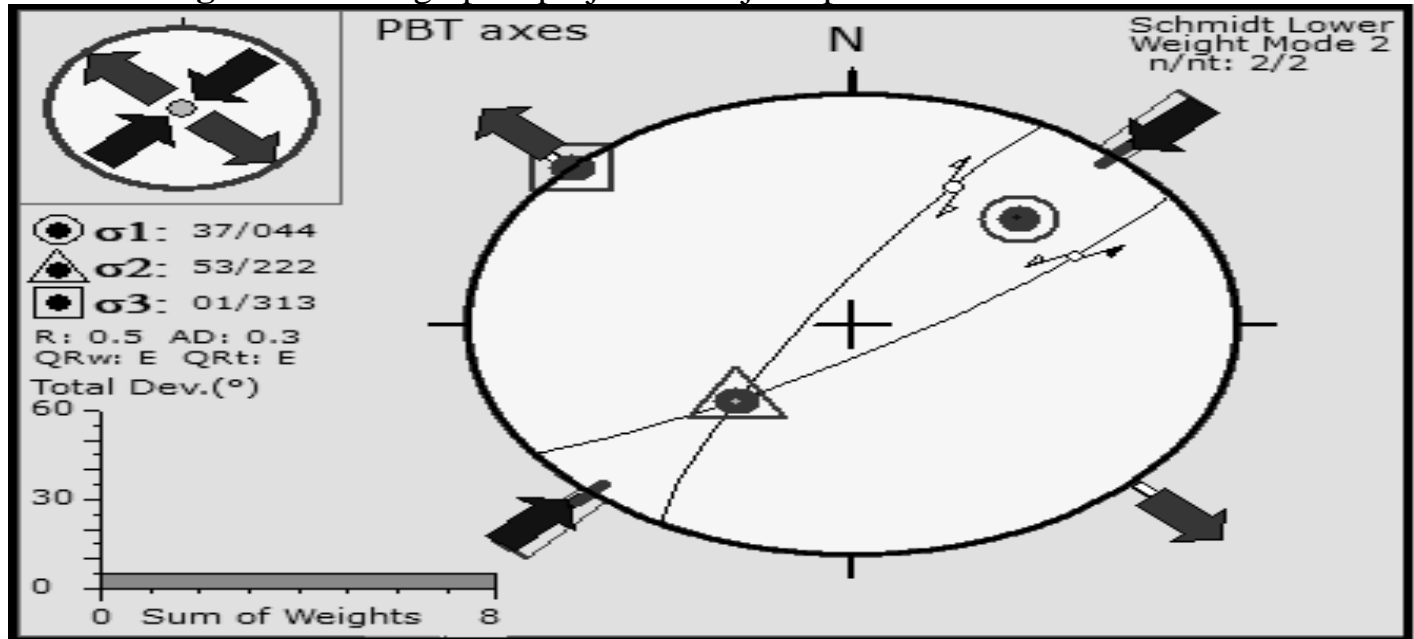

Figure 36-Paleostress analysis from (hk0) acute about (a) in traverse 4/ station 3. 


\section{Traverse 4/ station 4}

As shown in Figure- 37, (hk0) acute about (b) axis and (0kl) acute about (c) axis shear systems were recognized. The paleostresses which were analyzed from the shear joint systems are described below.

\section{Compressive stress}

Analyzed stress from (hk0) acute about (b) with $(\sigma 1)$ attitudes $\left(03^{\circ} / 323^{\circ}\right)$ was found in this station

(Figure- 38 A).

\section{Extensional stress}

Analyzed from (0kl) acute about (c) with $(\sigma 3)$ attitudes $\left(02^{\circ} / 132^{\circ}\right)$ (Figure- $\left.38 \mathrm{~B}\right)$. Individual (hk0) acute about (a) axis system as well as (ac) and (bc) sets were also recorded in this station.

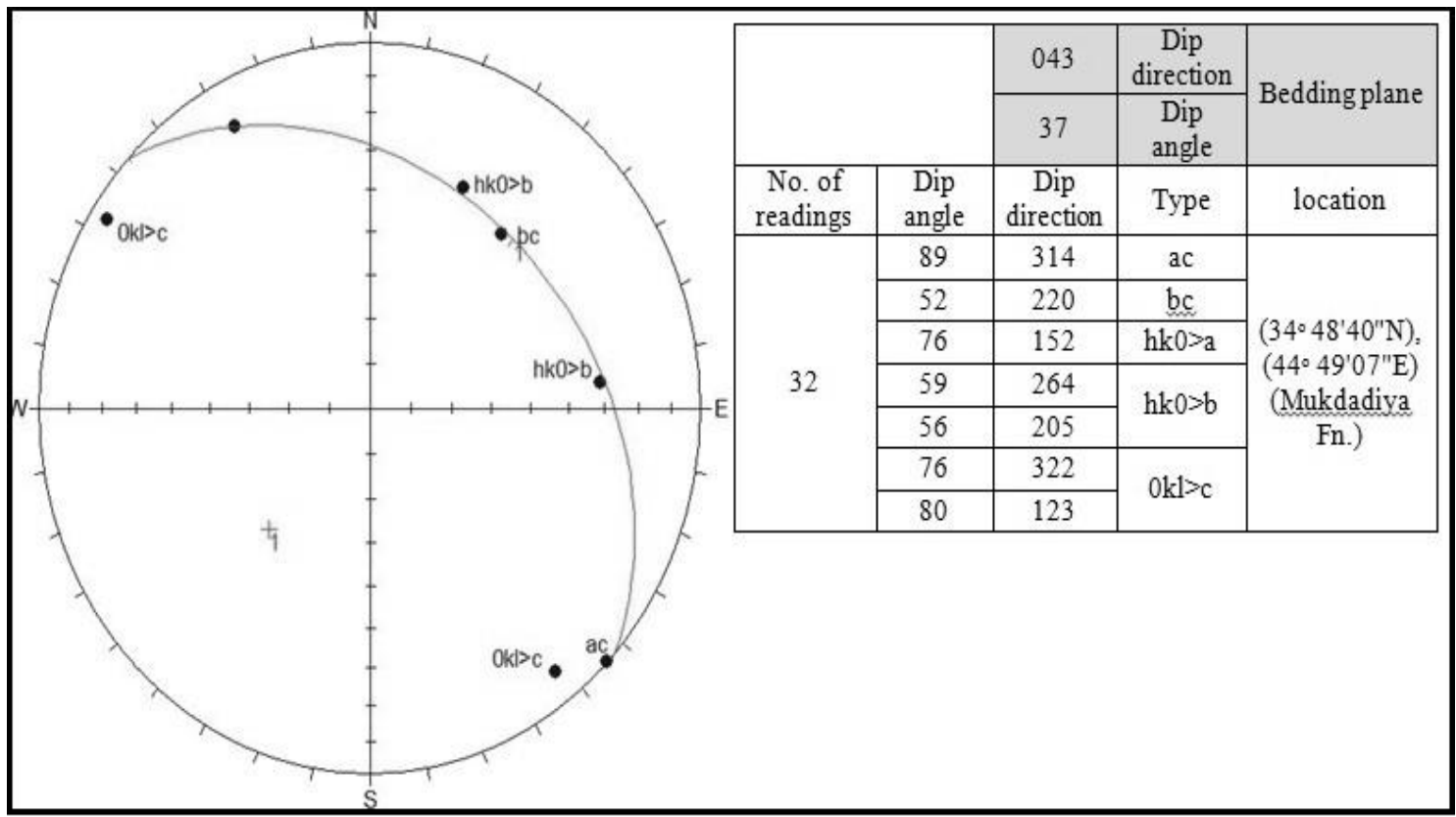

Figure 37-Stratigraphic projection of joint poles in traverse 4/ station 4

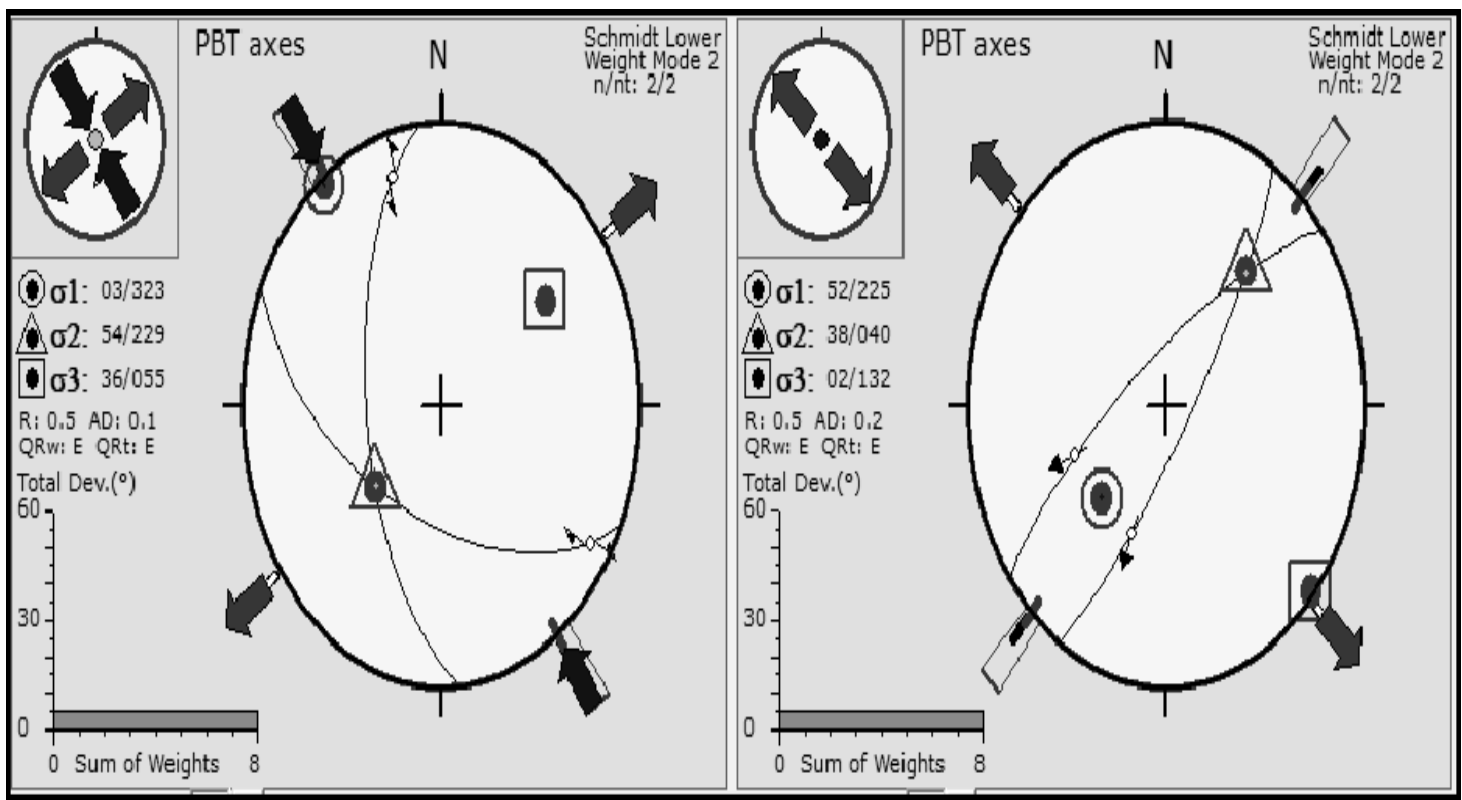

Figure 38 A-paleostress analysis from (hk0) acute about (b),; B: paleostress analysis from (0kl) acute about (c) in traverse 4/ station 4. 


\section{Traverse 5/ station 1}

As shown in Figure- 39, (h0l) acute about (a) axis and (h0l) acute about (c) axis shear systems were recognized. The paleostresses which were analyzed from the shear joint systems are described below.

\section{Compressive stress}

Analyzed stress from (h01) acute about (a) with $(\sigma 1)$ attitudes $\left(01^{\circ} / 016^{\circ}\right)$ was found in this station (Figure- 40 A).

\section{Extensional stress}

Analyzed stress from (h01) acute about (c) with $(\sigma 3)$ attitudes $\left(04 \% 1018^{\circ}\right)$ was found in this station (Figure-40 B). Individual (hk0) acute about (b) axis shear system as well as (ac) and (bc) sets were also recorded in this station.

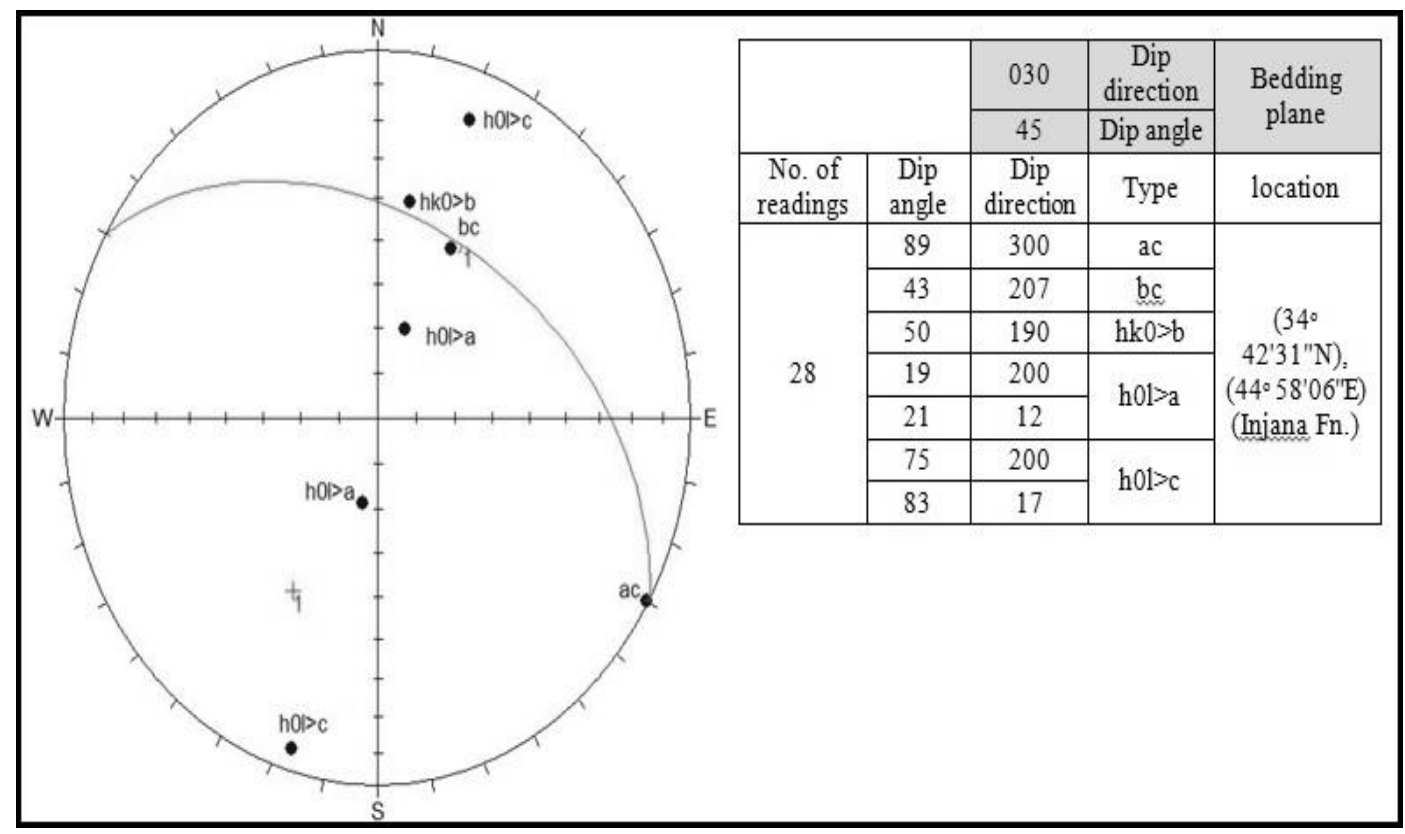

Figure 39-Stratigraphic projection of joint poles in traverse 5/ station 1 .

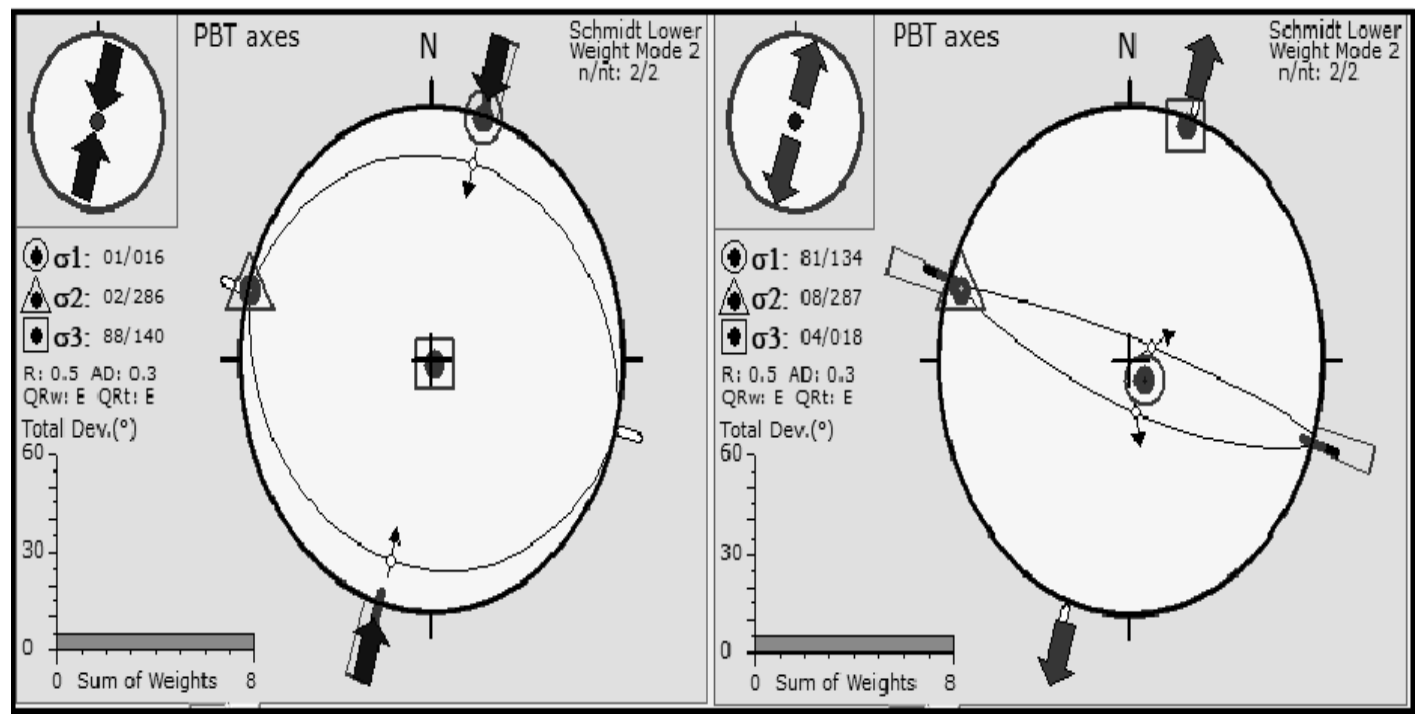

Figure 40 A-paleostress analysis from (h0l) acute about (a),; B: paleostress analysis from (h0l) acute about (c) in traverse 5/ station 1.

\section{Traverse 5/ station 2}

No conjugate shear joint systems were observed in this station (Figure- 41), while individual (hk0) acute about (a) axis, (hk0) acute about (b) axis, (h0l) acute about (c) axis systems, as well as (ac) and (bc) sets were recognized. 


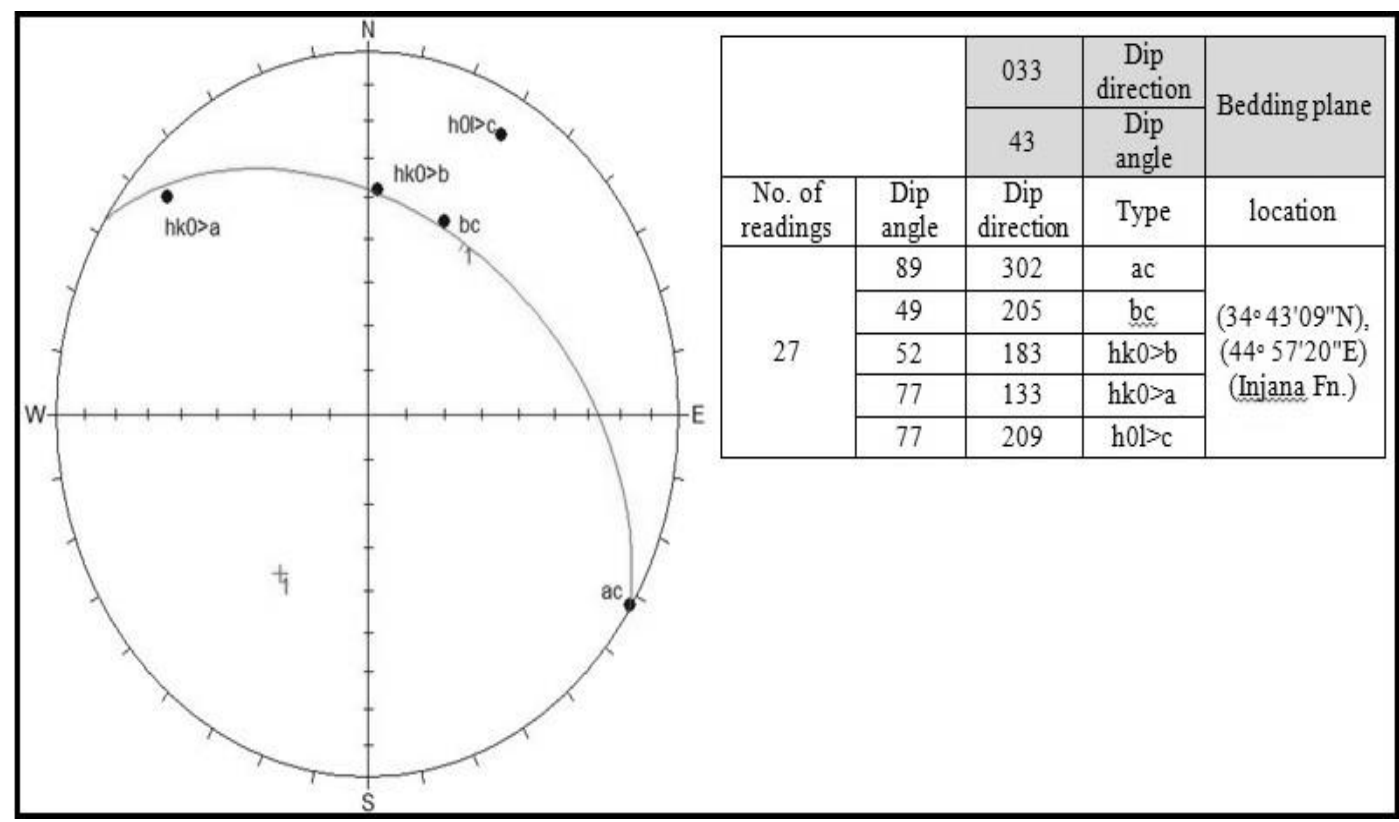

Figure 4-Stratigraphic projection of joint poles in traverse 5/ station 2.

\section{Traverse 5/ station 3}

NE-SW compressive stress from (h01) acute about (a) axis shear system with $(\sigma 1)$ attitude $\left(02^{\circ} / 015^{\circ}\right)$ was recognized in this station (Figure- 42 and B). Individual (hk0) acute about (b) axis system as well as (ac) and (bc) sets were also recognized. Figure- 43 A shows a field photo for (h0l) acute about (a) in the study area.

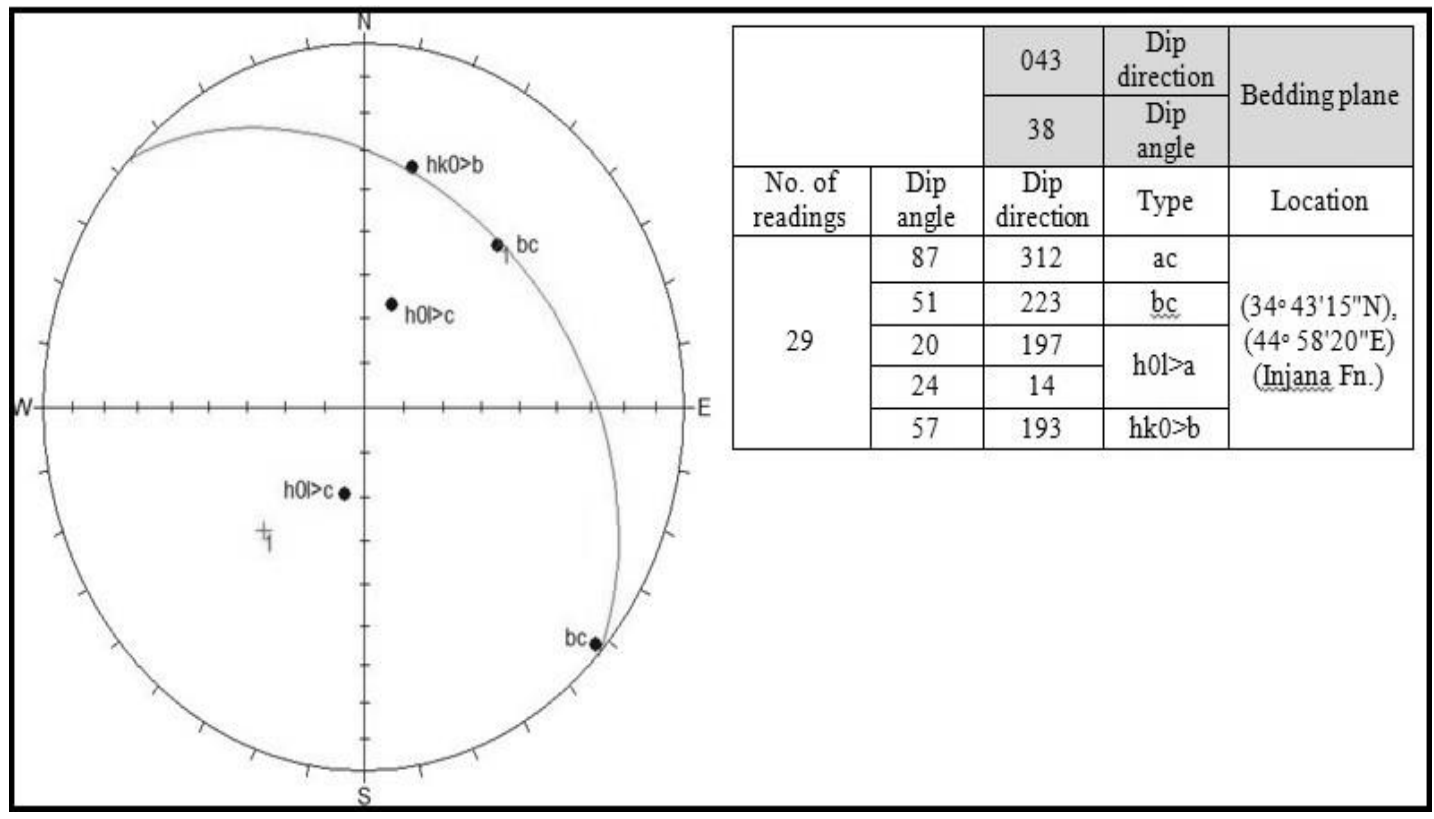

Figure 42-Stratigraphic projection of joint poles in traverse 5/ station 3 


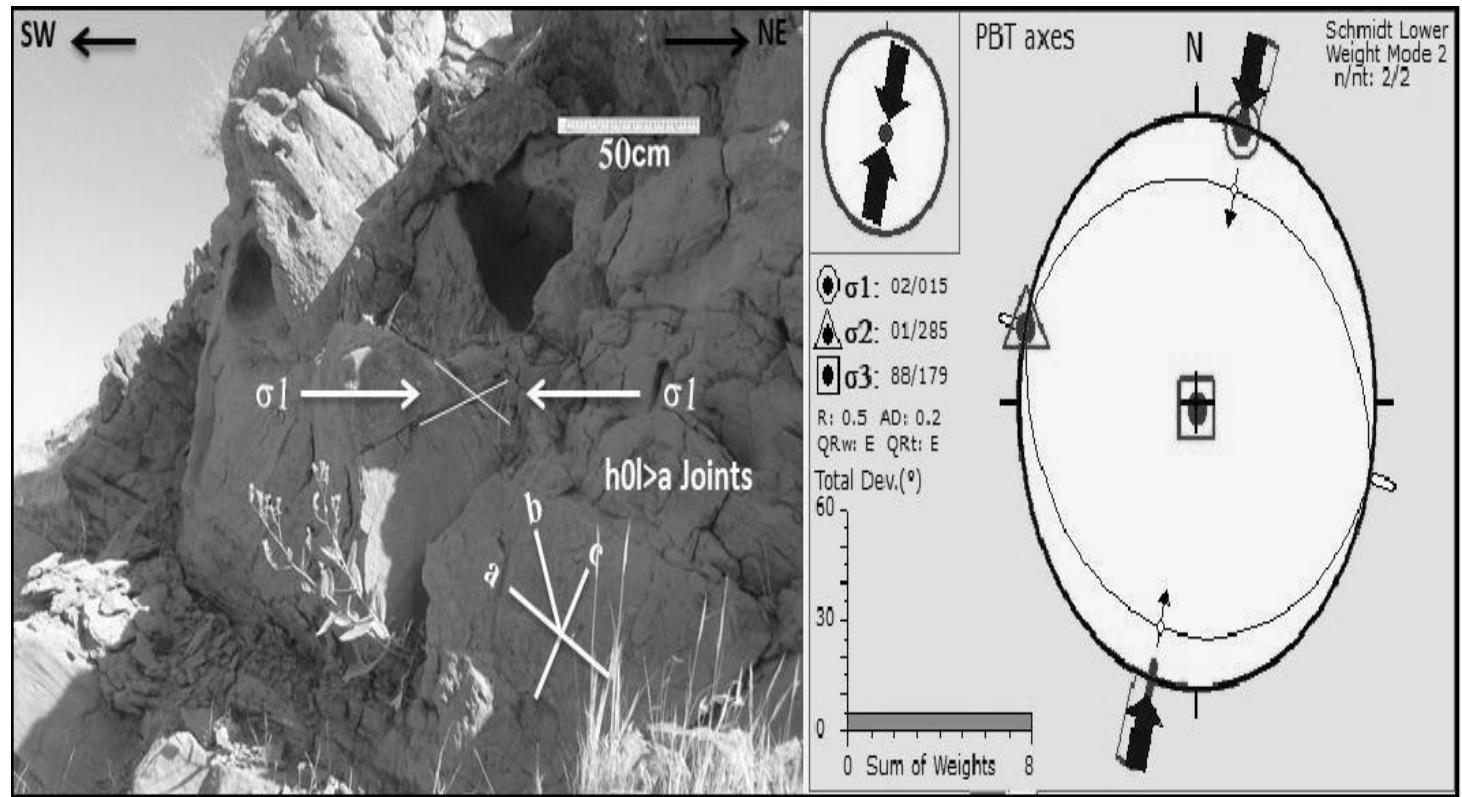

Figure 43 A-field photo of (h0l) acute about (a); B: paleostress analysis from (h0l) acute about (a) in traverse 5/ station 3 .

\section{Discussion}

Pulkhana anticline is considered as of a Fault - Propagation Fold type [27-31] . The dip of the south western limb of the anticline was previously reported to be about $70^{\circ}$, whereas the dip of the north eastern limb reached to $50^{\circ}$ [18]. Accordingly, Pulkhana anticline is classified as a gentle fold depending on its interlimb angle or as an upright fold depending on its dip of axial plane.

Pulkhana anticline intersects by many of joint sets, some of which are parallel to the hinge line of the fold and the others are vertical. From the study of these joints in Injana and Mukdadiya Formations across five traverses vertical to the strike of bedding, two types of orthogonal extensional joint sets (ac \& bc) and five types of shear joint systems (hk0>a, hk0>b, h0l>a, h0l>c \& $0 \mathrm{kl}>\mathrm{c}$ ) were distinguished.

Locating the maximum principal stress axis $(\sigma 1)$ from the acute bisectors of shear joints clarified that the most prevalent Paleostress directions are NE- SW and NW- SE. The main principle stress (NE- SW) was represented in the form of (ac) tension joints and (hk0>a \& h0l>a) shear joints, whereas the secondary principal stress (NW-SE) was represented in the form of (bc) tension joints and (hk0>b) shear joints. The (h0l>c \& $0 \mathrm{kl}>\mathrm{c})$ shear joints developed by the extensional phase were associated with NE- SW and NW- SE compressive stresses.

The formation of joints in multi- tectonic stages (i.e. different directions of maximum principal stress $\boldsymbol{\sigma} 1$ ) in the study area could be attributed to the oblique collision between the Arabian plate and Eurasian plate, as well as the counter clockwise rotation of the former relative to the latter.

\section{Conclusions}

1- Joints formed in different tectonic stages, in the study area are attributed to oblique collision of the Arabian and Eurasian plates, in addition to the counter clockwise rotation of the former relative to the latter plates.

2- Most probably, the growth of Pulkhana anticline started in the Middle Miocene as fold-related fault and developed in late Pliocene with influences by the conjugated strike slip fault.

3- Paleostress analysis for fracture structures indicated that the studied area was subjected throughout it geological history to the compression stresses (NE-SW trend) which was perpendicular to Pulkhana anticline axis.

4-Pulkhana anticline undergoes more than one tectonic stress regime, and this can be noticed from the different values of stress directions in the study area. the best evidence enhancing this scenario is the existence of (hkl) joints in the study area.

5-The study of joints in the NE limb of Pulkhana anticline clarified that the most prevalent paleostress directions are NE-SW and NW-SE. 
6-The NE-SW stress direction is considered as a primary compressive stress resulted from the oblique collision between the Arabian plate and Eurasian plate, which seems responsible for the initial folding in the study area. Whereas the NW-SE stress direction is considered as a secondary compressive stress developed during the relaxation event succeeding the primary compressive pulse.

7-The NE-SW extensional stress is considered as a releasing phase that is associated with the final uplift of the fold.

8-The NW-SE extensional face is considered as an extensional stress related to the primary NE-SW compressive stress.

9-The hkl joints could be resulted from the local stresses.

Finally, a detailed seismic reflection section is recommended to achieve a better view of the stratigraphy and to indicate a conclusive evidence of the occurrence of the strike slip movement.

\section{References}

1. Kaymakci, N. 2006. Kinematic development and paleostress analysis of the Denizli Basin (Western Turkey): Implications of spatial variation of relative paleostress magnitudes and orientations. Journal of Asian Earth Sciences, 27: 207-222.

2. Kayen, J. O, F. Maerten, D.D. Pollard 2011. Mechanical analysis of fault slip data: Implications for paleostress analysis. Journal of Structural Geology, 33(2): 78-91.

3. Jaeger, J.C., N.G.W. Cook 1969. Fundamentals of Rock Mechanics. Methuen, London.

4. Angelier, J. 1994. Fault slip analysis and paleostress reconstruction, Continental Deformation. Oxford: Pergamon Press., pp. 53-100.

5. Griggs , D., J. Handin 1960. Observations on fracture and a hypothesis of earthquakes In: Rock Deformation (A Symposium) Mere. Geol. Soc. Am., 9: 347-364.

6. Kehle, R. O. 1964. The determination of tectonic stresses through analysis of hydraulic well fracturing. Journal of Geophysical Research, 69: 259-273.

7. Abhijit, P., S. Dilip 2019: Stress regime changes in the Main Boundary Thrust zone, Eastern Himalaya,decoded from fault-slip analysis. Journal of Structural Geology, 120 (2019): 29-47

8. Pollard, D. D., S. D. Saltzer, A. M. Rubin. 1993. Stress inversion methods: Are they based on faulty assumptions. Journal of Structural Geology, 15: 145-154.

9. Homberg, C. , J. Angelier, F. Bergerat, L. Lacombe 2004: Using stress directions to identify slip events in fault systems. Earth and Planetary, Science Letters, 217: 409-424.

10. Pulisova, Z., J. Sokta, V. Śimonova. 2018. Multi-phase development of the faults and joints in the Súl'ov Conglomerates (Súl'ovské vrchy Mts., Slovakia): Implications for paleostress history. Mineralia Slovaca, Web ISSN 1338-3523, ISSN 0369-2086.

11. Wallace, R. E. 1951. Geometry of shearing stress and relation to faulting. Journal of Geology, 69 : $118-130$.

12. Igwe, I., I, A, Okonkwo. 2016. Application of paleostress analysis for the identification of potential instability precursors within the Benue Trough Nigeria. Geoenvironmental Disasters, 3 : $1-17$.

13. Pollard, D. D., P. Segall. 1980. Mechanisms of discontinuous faults, Journal of Geophysical Research, 85: 4337- 4350.

14. Dyer, J.R. 2003. Jointing in Sandstones. Arches National Park, Utah. PhD thesis, Leland Jr., Stanford University, Stanford, CA., 202p.

15. Ramsay, J. G., R. J. Lisle 2000. The techniques ofmodern structural geology, Applications of Continuum Mechanics in Structural Geology. Academic Press, London., Vol. 3:pp. 1025.

16. Jassim, S. Z., J. C. Goff. 2006. Geology of Iraq. Dolin, Prague and Moravian Museum Brano, Czech Republic, 341p.

17. Van der Pluijm, B. V., S. Marshak. 2004. Earth Structure: An Introduction to Structural Geology and Tectonic. WCB/McGraw- Hill, 656p.

18. Al-Naqib, Kh. M. 1960. Geology of the Southern area of Kirkuk Liwa. Second Arab Petroleum Con. Pub., London.

19. Al-Kadhimi, J. M. A., V. K. Sissakian et al. 1996. Tectonic Map of Iraq. 2nd Edition, Geo Survey, Baghdad, Iraq.

20. Omar, A. A. 2005. An Integral Structural and Tectonic Study of the Binabawi-Safin- Bradost Region in Iraqi Kurdistan. Unpublished Ph.D. Thesis, University of Salahadin, Erbil, 283p. 
21. Twiss, R. G. and Moores, E.M. 2007. Structural Geology. W.H. Freeman and Company, New York, 742p.

22. Hancock, P. L. 1985. Brittle Microtectonics: Principles and Practice. Journal of Structural Geology, 7: 437-457.

23. Hancock, P. L. and Atiya, M.s. 1979. Tectonic significance of mesofracture systems associated with the Lebanese segment of the Dead Sea transform fault. Journal of Structural Geology, 1: 143 $-153$.

24. Hancock, P.L., A. Alkadhi, N.A. Sha'at 1984. Regional joint sets in the Arabian platform as indicators of intra plate processes. Journal of Tectonics, 13: 27-43.

25. Ramsay, J. G., M. I. Huber 1987. The Technique of Modern Structural Geology. Vol. 2, Folds and Fractures, Academic Press, London, UK, 700p.

26. Al-Jumaily, I.S. 2004. Tectonic investigation of the brittle failure structures in the Foreland Folds Belt - northern Iraq, un.pub. Ph.D. Thesis, University of Mosul, Mosul, 238 p (In Arabic).

27. Ibrahim, A. O. 2009. Tectonic style and evolution of the NW segment of the Zagros Fold Thrust Belt, Sulaimani Governorate, Kurdistan region NE Iraq. Unpub. Ph.D. thesis, University of Sulaimani, Kurdistan region, Iraq,

28. Al-Jumaily, I.S., H. Gh. M., Adeeb, R. Kh. Al-Hamdani, M. S. Dawlat. 2012. Structural Analysis and Tectonic Interpretation of Brittle Failure Structures at Perat Anticline - NE Iraq. Iraq national jounal of earth science, 12(2): 17-42.

29. Al-Hakari, S. 2011. Paleostress analysis from brittle failure and structures in Dokan area ,Kurdistan region,NE of Iraq. Journal of Zankoy Sulaimani, 18(2Part-A): 283-210.

30. Al- Hakari, S. 2011. Geometric Analysis and Structural Evaluation of NW Sulaimani Area, Kurdistan Region, Iraq. Unpub. PhD. Thesis, University of Sulaimani, 358p.

31. Turnner, F. J. and Weiss, L.E. 1963. Structural Analysis of Metamorphic Tectonites. McGraw-Hill book Co. Inc., New York, 545 P. 